\title{
Thermal characterization of the active layer at the Limnopolar Lake CALM-S site on Byers Peninsula (Livingston Island), Antarctica
}

\author{
M. A. de Pablo ${ }^{1}$, M. Ramos ${ }^{2}$, and A. Molina ${ }^{1,3}$ \\ ${ }^{1}$ Department of Geology, Geography and Environment, University of Alcalá, Madrid, Spain \\ ${ }^{2}$ Department of Physics and Mathematics, University of Alcalá, Madrid, Spain \\ ${ }^{3}$ Centro de Astrobiología, CSIC/INTA, Madrid, Spain \\ Correspondence to: M. A. de Pablo (miguelangel.depablo@uah.es)
}

Received: 27 December 2013 - Published in Solid Earth Discuss.: 5 March 2014

Revised: 9 June 2014 - Accepted: 10 June 2014 - Published: 30 July 2014

\begin{abstract}
The Limnopolar Lake site (A25), of the Circumpolar Active Layer Monitoring -South network (CALM-S), is located on Byers Peninsula, where the active layer thickness is monitored systematically (by mechanical probing during the thawing season and by temperature devices continuously since 2009). Air, surface, snow and ground temperature devices have been installed to monitor ground thermal behavior, which is presented and characterized here. We use the air and ground mean daily temperature values to define the following parameters: maximum, minimum and mean temperatures, the zero annual thermal amplitude, and the depth and position of the top of the permafrost table. The freezing and thawing seasons (defining their starting dates as well as their length) and the existence of zero curtain periods have also been established. We also derive apparent thermal diffusivity and plot thermograms to study the thermal behavior of the ground at different depths and seasons. After this complete thermal characterization of the active layer, we propose the potential existence of a permafrost table at approximately $130 \mathrm{~cm}$ in depth as well as a former transitional layer above it, and discuss the role of water in connection with the thermal behavior of the ground during the study period.
\end{abstract}

\section{Introduction}

In early February 2009, a new monitoring site following the protocols of the Circumpolar Active Layer Monitoring South (CALM-S) program (e.g., Brown et al., 2000; Matsuoka and Humlum, 2003; Nelson et al., 2004; Matsuoka, 2006) was established in the Limnopolar basin $\left(62^{\circ} 34^{\prime} 35^{\prime \prime} \mathrm{S}\right.$, $61^{\circ} 13^{\prime} 07^{\prime \prime}$ W) (Fig. 1), on Byers Peninsula, Livingston Island (South Shetland archipelago), Antarctica (de Pablo et al., 2010). This CALM site, named "Limnopolar Lake", was officially added to the international CALM network in 2012 as the A25 site in Antarctica (Appendix A). The scientific objective of this experience is to contribute to the international network to study the effect of the global climate evolution of active layer thermal behavior, similarly to the CALM experiences located in Antarctica, like on Deception Island in the South Shetland archipelago (Ramos et al., 2009a, b, 2014; Ramos and Vieira, 2009; Vieira et al., 2010). To complete the active layer thickness (ALT) monitoring at the Limnopolar Lake CALM-S site, we installed different instruments (Table 1) to monitor the ground thermal behavior in two shallow boreholes ( 85 and $135 \mathrm{~cm}$ depth) as well as the air temperature and snow coverage (de Pablo et al., 2010, 2013a; Appendix A). The results of the first two years of ALT monitoring, at the Limnopolar Lake CALM-S site (de Pablo et al., 2013a), showed that the mechanical probing measurements correspond not to the ALT, but to the thawing depth (TD), because the bottom of the main borehole $(130 \mathrm{~cm}$ depth) does not reach the depth of the top of the permafrost. This conclusion is based on the thermal data from the sensors installed in the boreholes, showing that if permafrost existed, it should have been located deeper than $1.35 \mathrm{~m}$, i.e., deeper than the total depth of our boreholes and the standard steel probe $(100 \mathrm{~cm})$ that we use to measure the ALT by mechanical probing.

After five years of monitoring, now we have four complete years of air, surface, and ground temperature data (20092012). We use here some of those data (air and ground 
Table 1. Location and characteristics of the sensors installed at the Limnopolar Lake CALM site used here for the thermal characterization of the active layer.

\begin{tabular}{lccccc}
\hline Instrument & Sensor & $\begin{array}{c}\text { Measurement } \\
\text { height/depth } \\
(\mathrm{cm})\end{array}$ & $\begin{array}{c}\text { Frequency } \\
(\mathrm{h})\end{array}$ & $\begin{array}{c}\text { Resolution } \\
\left({ }^{\circ} \mathrm{C}\right)\end{array}$ & $\begin{array}{c}\text { Accuracy } \\
\left({ }^{\circ}\right)\end{array}$ \\
\hline Air temperature & $\begin{array}{c}\text { Tynitag } \\
\text { (Plus 2) }\end{array}$ & 160 & 1 & 0.02 & 0.35 \\
Shallow borehole \#1 & $\begin{array}{c}\text { iButton } \\
(\text { DS1922L) }\end{array}$ & $\begin{array}{c}(-) 2.5,5,10,20, \\
40,70,100,130\end{array}$ & 3 & 0.0625 & 0.50 \\
\hline
\end{tabular}

temperature from the deeper borehole) to conduct the first detailed analysis of the ground thermal behavior at this CALM site, extending and completing the preliminary results we obtained after the first two years of monitoring (de Pablo et al., 2013a). The objectives of this characterization are (1) to establish the annual ALT, (2) to analyze the presence of permafrost below the active layer, or the depth at which it should be located in case of existence, (3) to determine the depth of zero annual thermal amplitude depth, the thermal and surface offsets, the apparent thermal diffusivity of the ground, the freezing and thawing indexes and the $n$ factor, as well as their evolution along the time for the study period, and (4) to analyze the ground thermogram for each year to determine possible depths with different thermal behaviors. This thermal characterization is the basis for future research works in this CALM-S site, as well as for the comparative analysis with other nearby CALM-S sites on Deception and Livingston islands.

\section{Study area, data and methods}

\subsection{Study area}

The Limnopolar Lake CALM-S site is located on the smooth undulated plateau (approximately $105 \mathrm{ma.s.1.)}$ of Byers Peninsula, Livingston Island, near the SW shore of Limnopolar Lake (Fig. 1). This peninsula is the largest nonglaciated area in the South Shetland archipelago, and it lies near the climatic boundary of permafrost (Bockheim, 2006; Vieira et al., 2010), i.e., an area where permafrost and active layers are strongly sensitive to small temperature changes. The Byers Peninsula climate is cold, humid and windy. Mean wind speed is approximately $25 \mathrm{~km} \mathrm{hr}^{-1}$, although speeds could be as high as $139 \mathrm{~km} \mathrm{~h}^{-1}$ (Toro et al., 2007). The mean annual air temperature (MAAT) of the area is $-2.8^{\circ} \mathrm{C}$ (Bañon, 2001; Toro et al., 2007; Bañón et al., 2013), with extreme temperatures of -27.4 and $9.3^{\circ} \mathrm{C}$., although during the summer season MAAT is close to $1^{\circ} \mathrm{C}$. Total annual precipitation is estimated to be $800 \mathrm{~mm}$, and the snow covers the area for 7-8 months a year (de Pablo et al., 2013a). These climate conditions favor the existence of seasonal frozen ground, such as is revealed by the presence of extensive periglacial land forms in the area (patterned grounds, stone circles, etc.), which has been related to active layer dynamics and permafrost (López-Martínez et al., 1996; Serrano et al., 1996).

From the geological point of view, this region is characterized by Upper Jurassic-Lower Cretaceous volcanic, volcanoclastic and sedimentary materials and intrusive igneous bodies and Quaternary sediments (López-Martínez et al., 1996), the latter affected by periglacial, glacial, fluvial, and weathering processes that affected the bedrock after the deglaciation of the peninsula over 5000 years ago (Björck et al., 1996; Toro et al., 2013). The area surrounding the CALM site is characterized by a mantle of gravels, sands, and debris, locally forming stone circles, polygonal terrains, patterned ground, and other periglacial land forms (López-Martínez et al., 1996, 2012; Otero et al., 2013). The CALM-S site (Fig. 2) is located on the unsorted sandy gravel (locally forming patterned grounds) east-facing flank of a small smooth ridge inside the Limnopolar basin, approximately $2 \%$ in slope, with a variable water table (locally as shallow as $5 \mathrm{~cm}$ at the lower part of the site), and without outcrops.

\subsection{Data and methods}

Ground thermal characterization is based on the analysis of the data acquired by temperature sensors installed in early February 2009 to measure air, surface and ground temperatures. Those sensors are renewed yearly, during the Spanish Antarctic campaigns. The Limnopolar Lake CALM-S site includes different instruments (Table 1) to measure air temperature, snow thickness (by air temperature at different heights in a thermal snowmeter following the methodology outlined in Lewkowicz, 2008, and also applied by de Pablo et al., 2010), surface soil temperature and ground temperature at different depths inside two boreholes. Additionally, we also have an automatic photographic camera that takes one picture per day (at noon) to monitor the weather and snow cover evolution along the year.

In this work we analyze (1) the air temperature data acquired hourly by a Tinytag device from Gemini Co. and (2) ground temperature data acquired at different depths in the $135 \mathrm{~cm}$ depth borehole every three hours by the use of DS1922L iButtons devices from Maxim Co. All the 


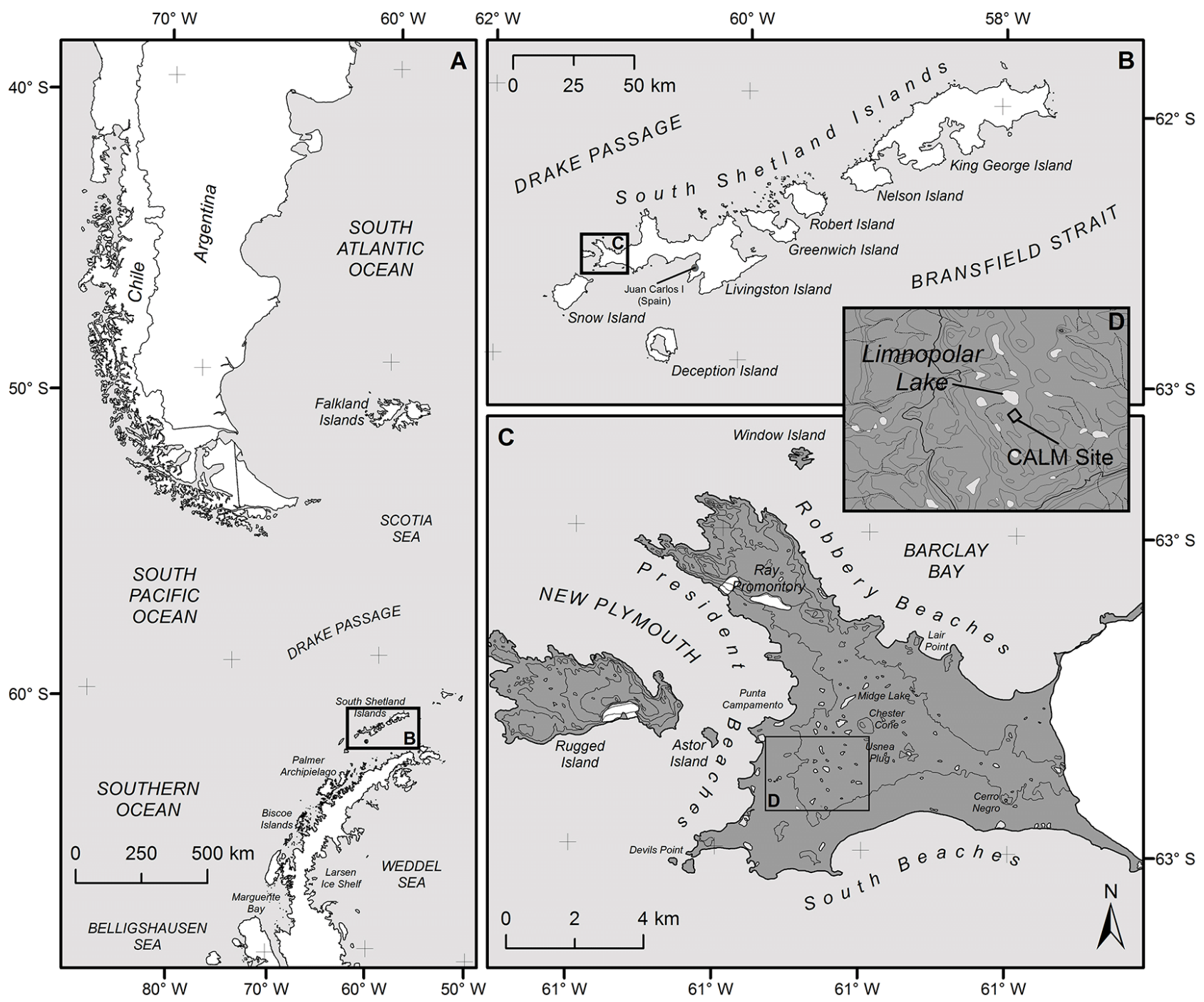

Figure 1. Location of the Limnopolar Lake CALM site (A25) on Byers Peninsula, Livingston Island, in the South Shetland archipelago, Antarctica.

characteristics of temperature devices are shown in Table 1 (and Appendix A). Raw air and ground temperature data (Fig. 3) were used to obtain mean daily values, and to calculate different thermal parameters as well as to produce plots to help us to understand the thermal behavior of the ground. Most of the calculations and plots presented here are based on the use of the preliminary version of CALM-DAT software (de Pablo et al., 2013b) and an Excel spreadsheet (by Microsoft). We produced a thermal profile of the ground, which is a key tool for deriving (a) active layer existence and its depth, (b) permafrost existence, and c) the depth of the zero annual thermal amplitude (Fig. 4). Annual maximum temperature values from the deeper sensors in the borehole $(40,70,100$ and $130 \mathrm{~cm})$ were fit to a linear curve versus depth in order to derive the maximum depth of the active layer by extrapolation, and the depth of the top of the permafrost. Temperature amplitudes (during a selected period) were plotted versus depth in order to fit an exponential curve (Fig. 4) and to derive the depth of the zero annual thermal amplitude by the use of the solution of the one-dimensional lineal heat transfer problem with the sinusoidal temporal evolution of the surface temperature in a homogeneous medium (e.g., Andersland and Ladanyi, 2003):

$A(x)=A_{0} \cdot e^{-\frac{x}{d}}$

$d=\sqrt{\frac{P \cdot \alpha}{\pi}}$

where $A$ is the thermal amplitude (in ${ }^{\circ} \mathrm{C}$ ) and $P$ the period (in s) at the surface temperature evolution, $x$ is the position variable, depth (in $\mathrm{m}$ ), and $\alpha$ the thermal diffusivity (in $\mathrm{m}^{2} \mathrm{~s}^{-1}$ ).

On the other hand, mean air and ground temperatures were used to calculate thermal and surface offsets (Fig. 5). Surface 


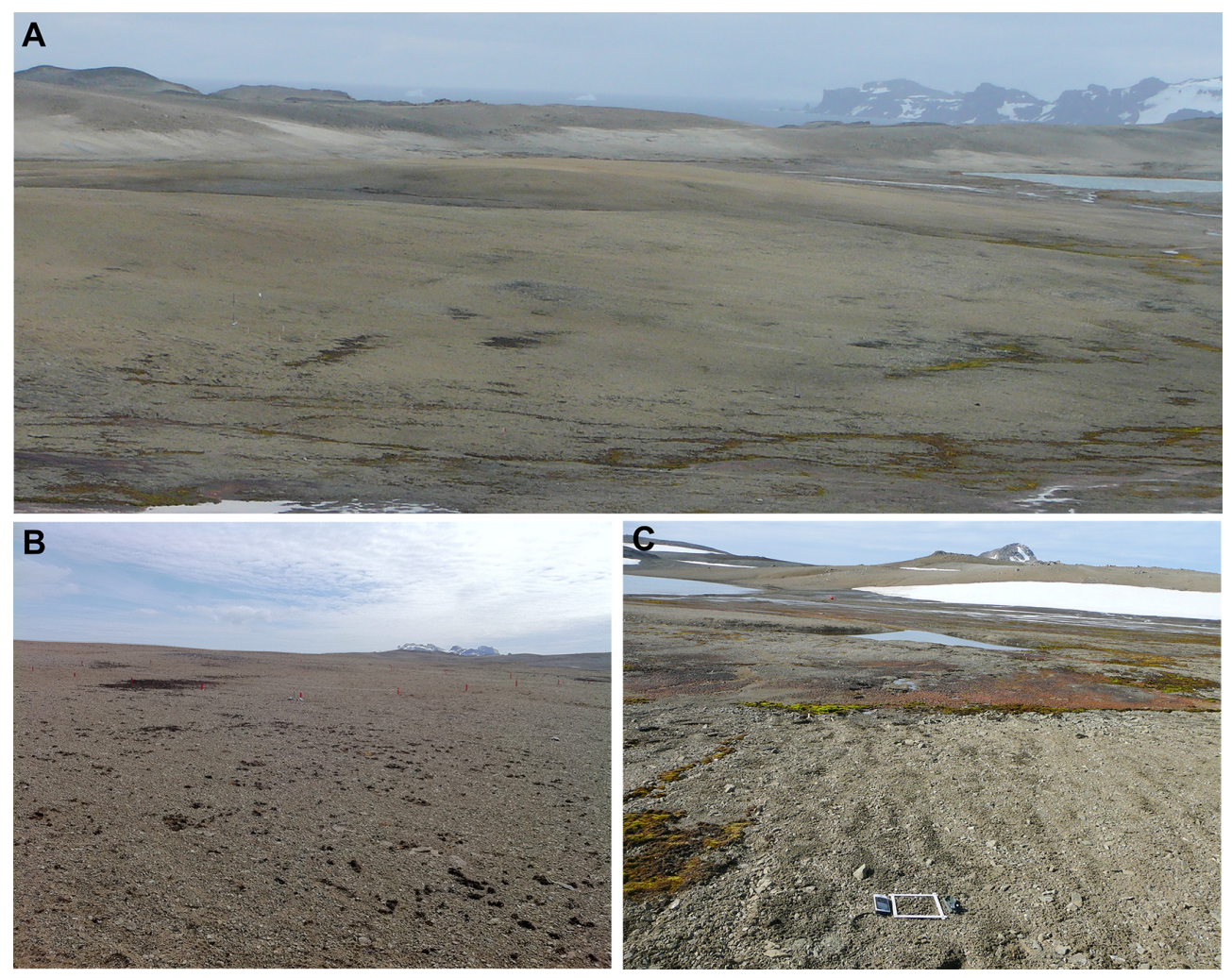

Figure 2. (A) Picture of the area in which the CALM site is located on the SW flank of Limnopolar Lake, in a smooth and gently sloped $(<2 \%)$ terrain without vegetal coverage. The surface is characterized by fine to coarse materials (B), sometimes organized into patterned grounds, with the presence of ponds and small moss patches $(\mathbf{C})$.

offset has been calculated in two different ways: first as the difference between the mean annual temperatures at the surface $(2.5 \mathrm{~cm}$ depth) and the mean annual air temperature $(160 \mathrm{~cm}$ height). However, the thermal offset, which is defined as the difference between the mean annual temperature at the surface and the temperature at the top of the permafrost, could not be calculated directly since our previous results point to us not reaching the top of the permafrost in the $130 \mathrm{~cm}$ deep borehole (de Pablo et al., 2013a). In spite of that, we approach the thermal offset by using in its calculation the mean annual temperature of the ground at the deeper point in our borehole $(130 \mathrm{~cm})$. The result should be considered to be a better approach than a real thermal offset.

Freezing and thawing periods were defined as the date on which the mean daily air and ground temperatures remain below $0^{\circ} \mathrm{C}$ or above it, respectively, ignoring short travels through this temperature inside each period. The length of each period is shown in days (Fig. 6). We did not consider the length of the 2009 thawing and 2012 freezing seasons due to the available data being incomplete for those periods, because instruments were installed in the middle of the 2009 thawing season, and the last data were recovered during the 2012 freezing season. Since the data do not represent the complete season, we have not used them to calculate sea- son length in days, but they were used to define the dates of the seasons' limits, as well as the zero curtain periods. We also defined the limits of the zero curtain periods, which are the periods (at the end of the thawing and at the end of the freezing seasons) in which the ground temperature reflects the zero curtain effect, i.e., when the phase transition between water and ice (or vice versa) is retarded because of the release of the latent heat (Fig. 7). These periods are defined as the date on which the mean daily ground temperatures remain near $0{ }^{\circ} \mathrm{C}$ for a few days; meanwhile the air temperature varies. The length in days of each one of those periods (zero curtain) at different depths was plotted to analyze their existence, behavior and evolution (Fig. 7).

Mean daily temperatures of the air and the ground were also used to calculate and plot (Fig. 8) the freezing and thawing indexes (FDD and TDD, respectively), such as the summation of the negative $\left(<0^{\circ} \mathrm{C}\right)$ (FDD) and positive $\left(>0{ }^{\circ} \mathrm{C}\right)$ (TDD) temperatures along the freezing and thawing seasons, respectively.

$$
\begin{aligned}
& \mathrm{FDD}=\sum_{\text {Freezing }}\left(\bar{T}<0{ }^{\circ} \mathrm{C}\right) \\
& \mathrm{TDD}=\sum_{\text {Thawing }}\left(\bar{T}>0{ }^{\circ} \mathrm{C}\right)
\end{aligned}
$$




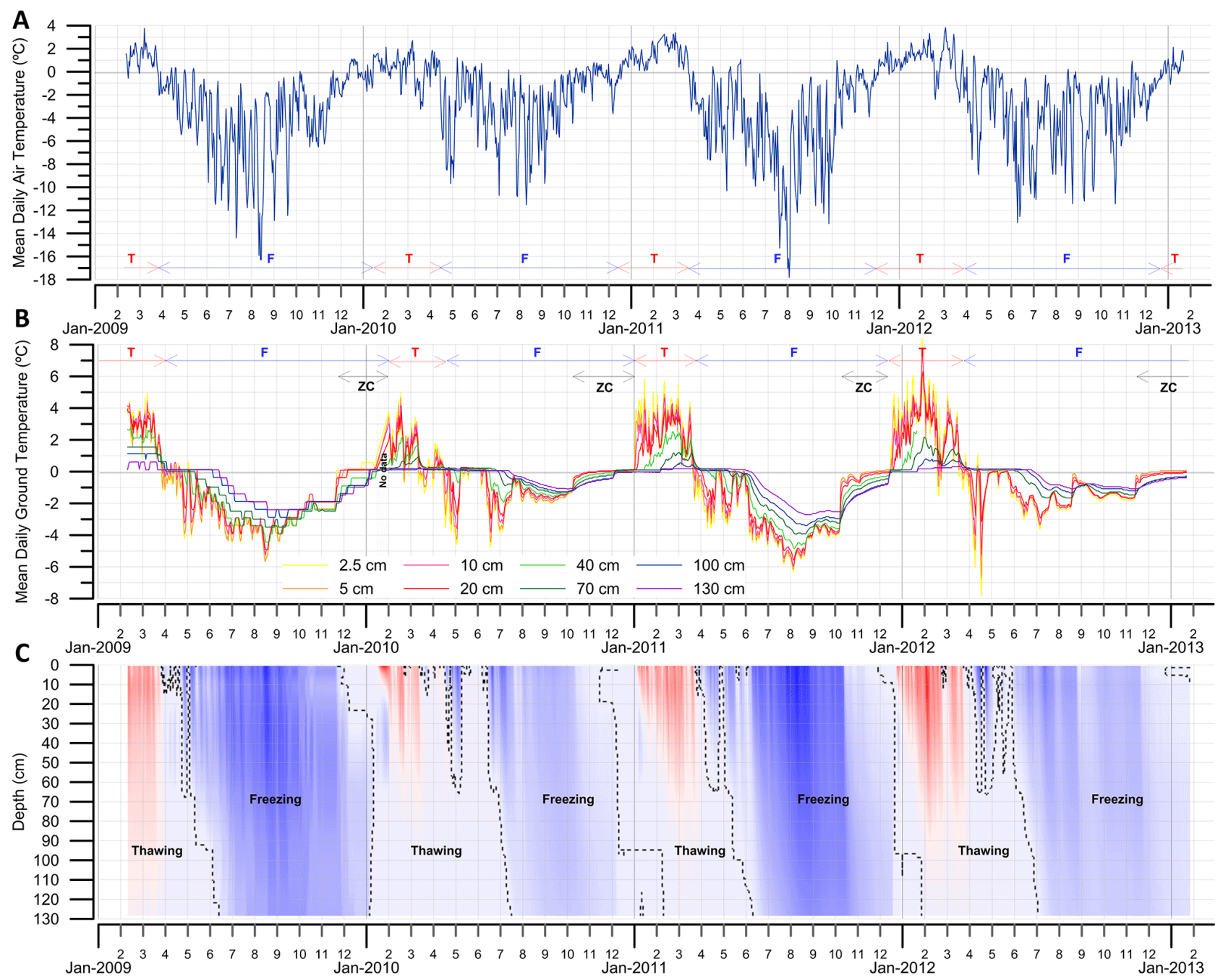

Figure 3. Mean daily temperature data of the air (A) and the ground at different depths in the $130 \mathrm{~cm}$ depth borehole (B) of the Limnopolar Lake CALM site, showing the freezing $(\mathrm{F})$, thawing $(\mathrm{T})$ and zero curtain periods $(\mathrm{ZC})$, and $(\mathbf{C})$ the resulting thermogram for the monitoring period.

where $T$ is the mean daily temperature $\left({ }^{\circ} \mathrm{C}\right)$.

In order to compare with the previously described calculation for the depth of the top of the permafrost, the thawing index was plotted versus depth and fit to calculate by extrapolation the depth at which the ground has no positive temperatures (Fig. 8). Freezing and thawing indexes of the surface (calculated by the use of the temperature data at the shallower depth in the borehole: $2.5 \mathrm{~cm}$ depth) and the air $(160 \mathrm{~cm}$ height) were used to calculate and plot (Fig. 9) the freezing and thawing $n$ factors ( $n_{\mathrm{f}}$ and $n_{\mathrm{t}}$, respectively) as the ratio between them (e.g., Lunardini, 1978; Andersland and Ladanyi, 2003).

$n_{\mathrm{f}}=\frac{\text { FDD surface }}{\text { FDD air }}$ $n_{\mathrm{t}}=\frac{\text { TDD surface }}{\text { TDD air }}$

The $n$ factor provides a parameter that could be used to analyze, among other factors, the isolation between the atmosphere and the ground primarily caused by snow cover (Lunardini, 1978), since a thick enough snow layer produces a buffer effect on the transmission of the temperature from the atmosphere to the ground. In this sense, to analyze the $n$ factor and its evolution provides an idea of the snow cover effect on the thermal behavior of the ground.

Plots of cumulative daily $n$ factors have been developed to characterize and compare the evolution of the freezing and thawing periods in the study area, as well as to define the mean value that characterizes the thermal behavior of the 

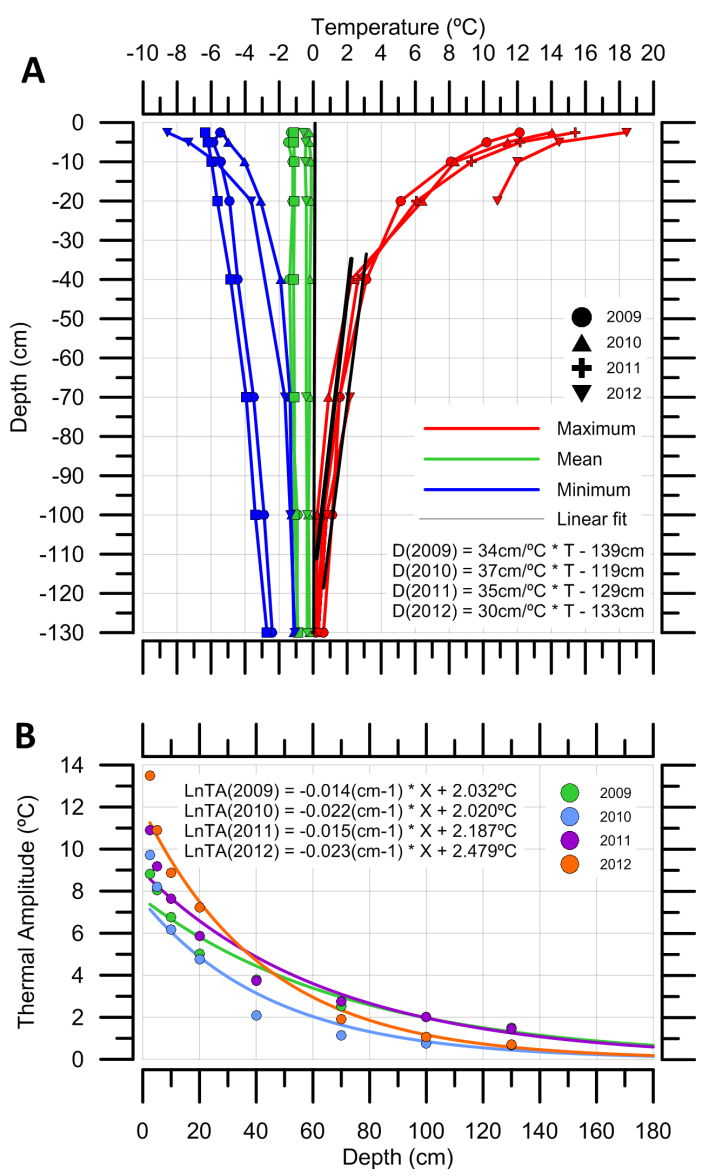

Figure 4. (A) Thermal profiles showing minimum (blue), mean (green) and maximum (red) temperatures of the ground at different depths in 2009, 2010, 2011 and 2012, and equations of the linear fitting curve to the maximum temperatures. (B) Exponential fitting curves to the thermal amplitudes of the ground at different depths, and their corresponding equations, to calculate the top of the permafrost depth.

atmospheric boundary layer and soil surface interaction in the area.

Apparent thermal diffusivity for the freezing and thawing seasons was also calculated. We used the temperature of the ground at different depths until $20 \mathrm{~cm}$, by selecting periods of a few days in length for each season in which the temperature evolution showed a well-defined sinusoidal wave, produced by solar daily or non-seasonal air temperature variation, to calculate the soil's apparent thermal diffusivity. We then used the available data in this period to derive, applying Eqs. (1) and (2) at two different depths (X), the thermal diffusivity $(\alpha)$ by means of the amplitude method summarized in the next equation (e.g., Andersland and Ladanyi, 2003):

$\alpha=\frac{\pi}{P} \cdot\left[\frac{X_{2}-X_{1}}{\ln \left(\frac{A_{X_{1}}}{A_{X_{2}}}\right)}\right]^{2}$,
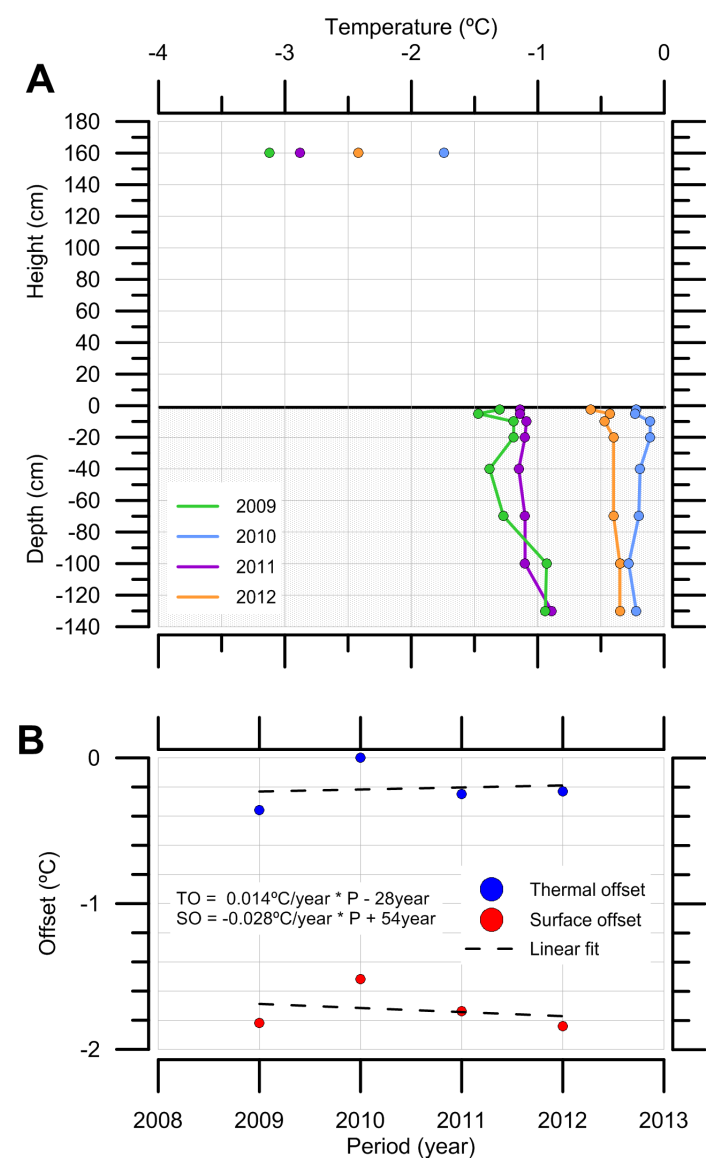

Figure 5. (A) Mean annual air and ground temperatures at different depths used to derive the thermal and surface offset, and (B) their evolution along the study period.

where $P$ is the considered period (in s), $X$ is the space variable, depths (in $\mathrm{m}$ ), and $A$ the thermal amplitude (in ${ }^{\circ} \mathrm{C}$ ). Finally, raw ground temperature data were plotted in a thermogram (temperature at depth versus time) as well as the $0{ }^{\circ} \mathrm{C}$ isotherm in order to study the ground thermal behavior and its temporal evolution (Fig. 3).

\section{Results}

\subsection{Freezing and thawing seasons}

Plots of air and ground temperatures (Fig. 3) made it possible to define the limits of the main thermal seasons that characterize this polar region: freezing and thawing. The limit dates of those seasons are defined by the change in the temperature from positive to negative (start of the freezing period), or from negative to positive (start of the thawing period).

The starting dates of each period (Table 2) are approximately similar for the upper depths, but somewhat different in the lower ones, following the slopes previously calculated of 50 and $40 \mathrm{~d} \mathrm{~m}^{-1}$ in difference. In general, the freezing 


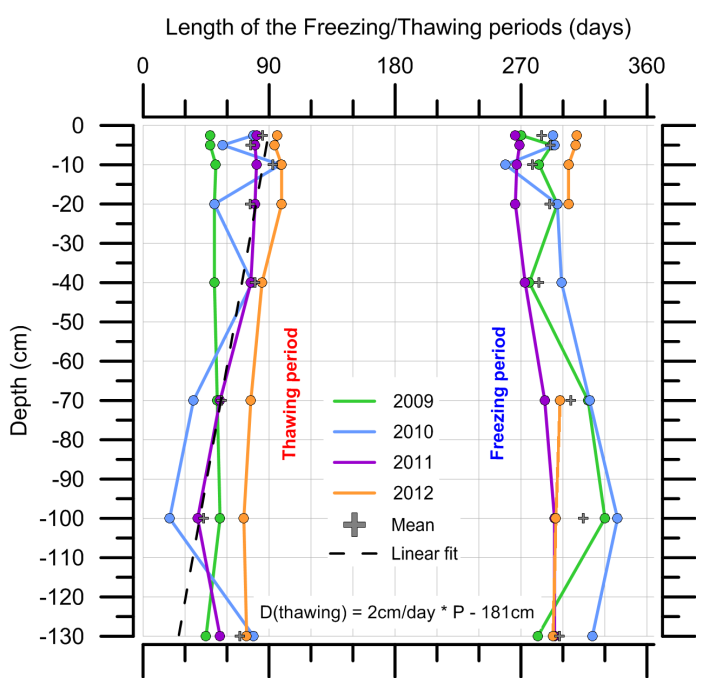

Figure 6. Freezing and thawing period lengths (in days) for each year of the study period, and linear fitting used to derive the depth at which the ground does not have thaw processes, i.e., the depth of the top of the permafrost.

season starts between 13 March and 22 March at the surface, and between 10 June and 15 July at $130 \mathrm{~cm}$ in depth. The thawing season starts between 13 December and 31 December at the surface, and between 2 January and 6 February at $130 \mathrm{~cm}$ in depth. The longer freezing season occurred in 2010, while the longer thawing season was registered in 2012.

The ground at different depths shows thawing and freezing periods with well-defined lengths, of approximately $73 \pm 2$ days for the thawing season and $292 \pm 2$ days for the freezing season (Table 3). Those values change with depth in the borehole, from the surface to $130 \mathrm{~cm}$ in depth, ranging from $43 \pm 2$ to $93 \pm 2$ days in the case of the thawing season, and from $278 \pm 2$ to $314 \pm 2$ days in the case of the freezing season. In general, the shorter freezing period and the longer thawing period occur in the surface, trending to invert with depth due to the soil thermal inertia. The different behavior is observed at $130 \mathrm{~cm}$ in depth, with similar lengths of the freezing and thawing periods than at the surface (Fig. 6). In general, the thawing season shows more variable lengths than the freezing season. The fitted linear curve to the mean season length values returns slopes of approximately $50 \mathrm{~d} \mathrm{~m}^{-1}$ and $40 \mathrm{~d} \mathrm{~m}^{-1}$ in the variation of the thawing and freezing season lengths, respectively. We also used the lineal fitting curve of the thawing period to deduce the depth at which the thawing period is 0 days in length, or, which is the same, the depth of the top of the permafrost. The result is approximately $180 \mathrm{~cm}$ in depth. However, this approach does not consider the data of the deeper sensor $(130 \mathrm{~cm})$, which have a higher length of the thawing season and a shorter one of the freezing period than expected, i.e., they do not fit the trend of the depths above it. By the use of the fitting curve of the

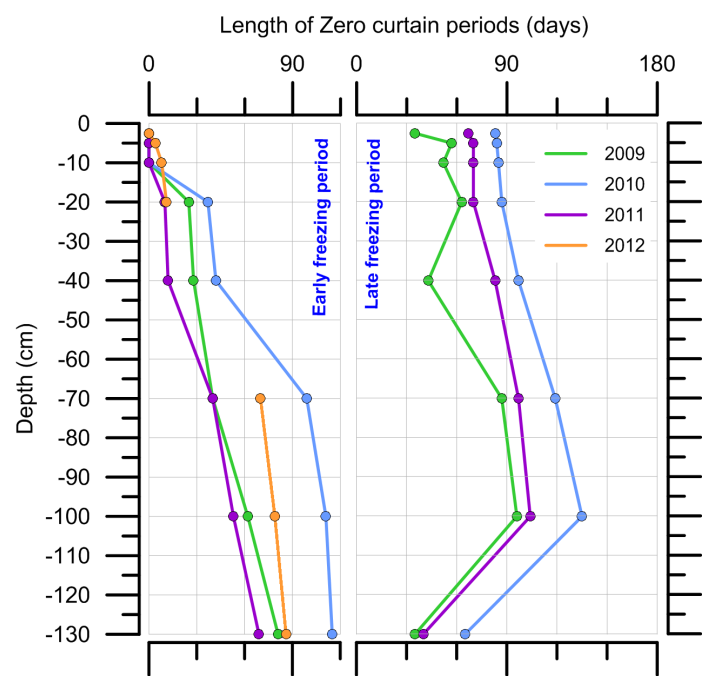

Figure 7. Length (in days) of the zero curtain periods at different depths during the early (left) and late (right) freezing periods.

freezing length, we obtain a depth of $215 \mathrm{~cm}$ for the depth at which the length of the freezing season is 365 days.

\subsection{Zero curtain periods}

In all years, at the end of the freezing period, we observed in the mean daily temperatures the existence of zero curtain periods (Fig. 3). They tend to start on the same day at all depths, between 7 October and 19 November, or, in general, with a difference smaller than 10 days (Table 4). Only the deeper sectors, in selected years, show a delay, starting the zero curtain periods in early December. The zero curtain period starts with an increase in the temperatures at all depths at the same time to reach $0{ }^{\circ} \mathrm{C}$, remaining at that temperature for a period of approximately $76 \pm 2$ days (Fig. 7). However, there is a wide variability between the different depths, and for the different years, ranging from $35 \pm 2$ to $135 \pm 2$ days in length. The zero curtain periods are longer in depth (70 to $100 \mathrm{~cm}$ ), except that the deeper ground in the borehole shows lengths similar to, or even smaller than, the zero curtain period lengths in the shallower ground.

Moreover, of the zero curtain period at the end of the freezing period (spring season), we observed that, except at shallower depths, the ground shows similar zero curtain periods during the fall season, in the early freezing season. They are typically shorter, approximately $32 \pm 2$ days in length, but ranging from $25 \pm 2$ to $115 \pm 2$ days (Fig. 7). In contrast to the zero curtain periods during the fall, their lengths increase with depth and they are not recognizable at the shallower depths. Moreover, of this pattern, we observe abrupt differences in the period length at 20 and $70 \mathrm{~cm}$ in depth, except in 2012. These zero curtain periods were longer in 2010 and 2012 (Table 4). 

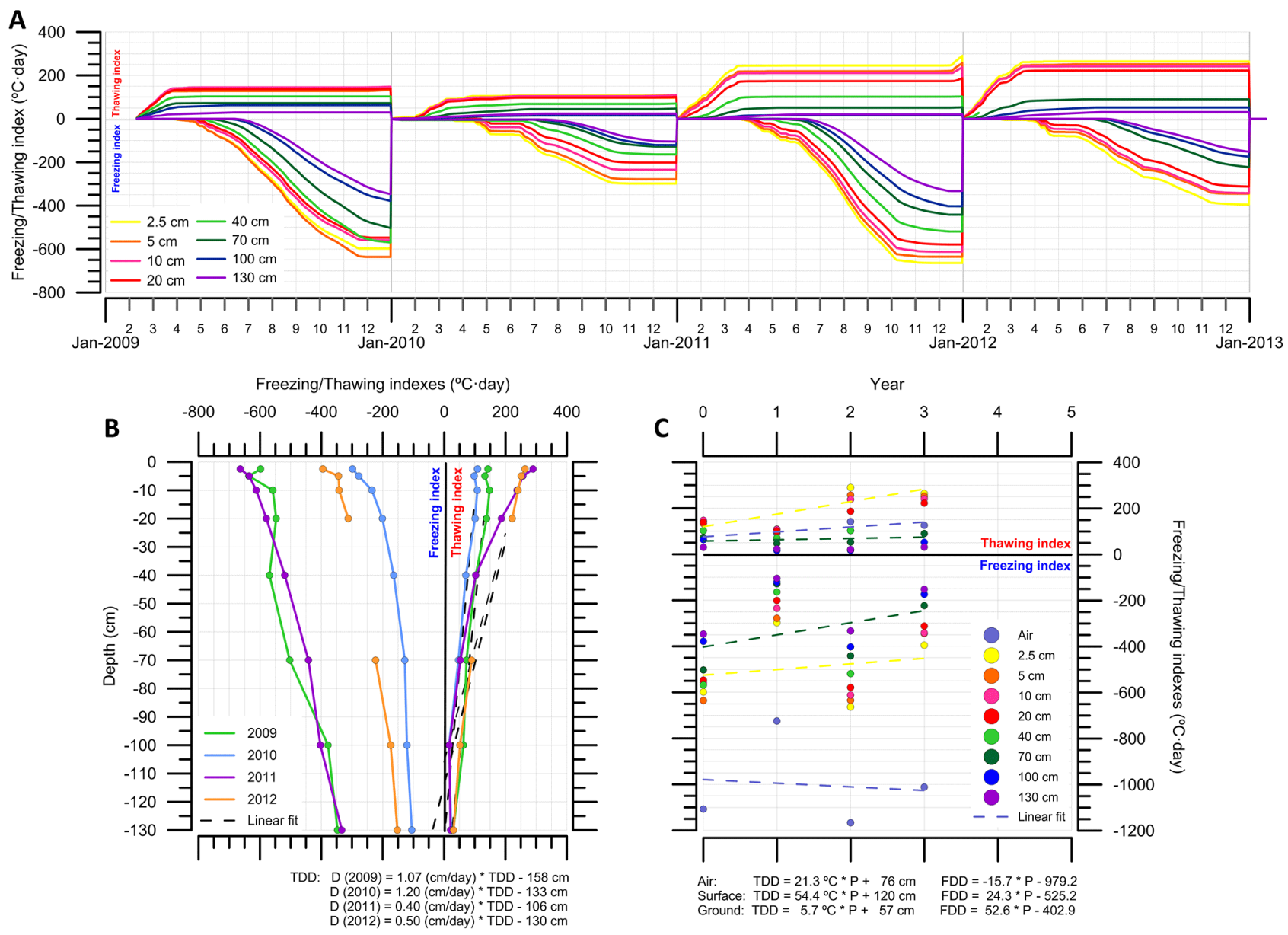

Figure 8. (A) Annual accumulated FDD and TDD indexes for the ground at different depths. (B) FDD and TDD evolution in the study period with linear fitting curves for the air, surface and $70 \mathrm{~cm}$ depth. FDD and TDD profiles (C) allow for the deduction of a negative balance for each year, and linear fitting to TDD allows for the deduction of the theoretical depth with null thawing, i.e., the depth of the top of the permafrost.

A peculiar event was observed in 2012 when data reflect two zero curtain periods, on 19 August and on 12 November 2012. The first event was approximately one month long, finishing on 8 September due to a new freezing process. Only the second one was long enough to conduct possibly to the complete thawing of the ground. However, this process was not completed at the date on which the data sensors were recovered on 22 January 2013, clearly later than the end of the freezing season in the previous years (Table 4).

\subsection{Freezing and thawing indexes}

Freezing and thawing indexes (FDD and TDD, respectively) were calculated by the use of Eqs. (3) and (4) and are summarized in Table 5. The resulting FDD values for the air range from $-730 \pm 73$ to $-1170 \pm 117^{\circ} \mathrm{C}$ a day, while TDD values range from $72 \pm 7$ to $142 \pm 14{ }^{\circ} \mathrm{C}$ a day. On the other hand, the FDD for the ground ranges from $-664 \pm 30$ to $-105 \pm 50{ }^{\circ} \mathrm{C}$ a day and the TDD ranges from 21 to $290{ }^{\circ} \mathrm{C}$ a day. In general, higher values are reached at the surface, decreasing in depth (Fig. 8), and the air has higher (absolute) values of FDD but lower values of TDD: in the first case, about double the higher FDD of the ground (at the surface), while the TDD values are similar to those reached between 20 and $70 \mathrm{~cm}$ in depth.

The evolution of those indexes along the study period shows an abrupt decrease in FDD and TDD values in 2010, and a slight decrease in 2012 (Fig. 8). Linear fitting reveals mean slopes of $21.3 \pm 2.0$ and $23.7 \pm 14.0{ }^{\circ} \mathrm{C}$ day $\mathrm{yr}^{-1}$ for the TDD in the air and on the ground, respectively, and mean slopes of $15.7 \pm 2.0$ and $32.2 \pm 16.0{ }^{\circ} \mathrm{C}$ day $\mathrm{yr}^{-1}$ for the FDD in the air and on the ground, respectively (Table 6). In the case of TDD, linear fitting of the curves rises near the $0{ }^{\circ} \mathrm{C}$ day value at around 105 and $158 \mathrm{~cm}$ in depth (Fig. 8).

On the other hand, the difference between FDD and TDD provides a negative balance for all depths and years (Fig. 8). In general this balance shows higher absolute values 
Table 2. Starting date (day/month/year) of the freezing (F) and thawing (T) seasons at different depths (in $\mathrm{cm}$ ).

\begin{tabular}{cccccccc}
\hline Depth & $\begin{array}{c}2009 \\
\mathrm{~F}\end{array}$ & $\mathrm{~T}$ & $\mathrm{~F}$ & $\mathrm{~T}$ & $\mathrm{~F}$ & $\mathrm{~T}$ & $\mathrm{~F}$ \\
\hline-2.5 & 29 Mar 2009 & 24 Dec 2009 & 13 Mar 2010 & 31 Dec 2010 & 22 Mar 2011 & 13 Dec 2011 & 18 Mar 2012 \\
-5 & 29 Mar 2009 & 15 Jan 2010 & 13 Mar 2010 & 1 Jan 2011 & 22 Mar 2011 & 16 Dec 2011 & 19 Mar 2012 \\
-10 & 2 Apr 2009 & 10 Jan 2010 & 18 Apr 2010 & 2 Jan 2011 & 24 Mar 2011 & 16 Dec 2011 & 24 Mar 2012 \\
-20 & 1 Apr 2009 & No data & 14 Mar 2010 & 4 Jan 2011 & 25 Mar 2011 & 16 Dec 2011 & 24 Mar 2012 \\
-40 & 1 Apr 2009 & 2 Jan 2010 & 21 Mar 2010 & 14 Jan 2011 & 1 Apr 2011 & 30 Dec 2011 & 24 Mar 2012 \\
-70 & 3 Apr 2009 & 15 Feb 2010 & 23 Mar 2010 & 5 Feb 2011 & 1 Apr 2011 & 13 Jan 2012 & 30 Mar 2012 \\
-100 & 5 Apr 2009 & 1 Mar 2010 & 20 Mar 2010 & 22 Feb 2011 & 2 Apr 2011 & 21 Jan 2012 & 2 Apr 2012 \\
-130 & 26 Mar 2009 & 2 Jan 2010 & No data & 6 Feb 2011 & 2 Apr 2011 & 21 Jan 2012 & 4 Apr 2012 \\
\hline
\end{tabular}

Table 3. Length in days of the freezing $(\mathrm{F})$ and thawing $(\mathrm{T})$ seasons at different depths (in $\mathrm{cm}$ ), and mean value for the studied period.

\begin{tabular}{ccccccccccc}
\hline Depth & \multicolumn{2}{c}{2009} & \multicolumn{2}{c}{2010} & \multicolumn{2}{c}{2011} & \multicolumn{2}{c}{2012} & \multicolumn{2}{c}{ Mean } \\
& $\mathrm{T}^{\mathrm{a}}$ & $\mathrm{F}$ & $\mathrm{T}$ & $\mathrm{F}$ & $\mathrm{T}$ & $\mathrm{F}$ & $\mathrm{T}$ & $\mathrm{F}^{\mathrm{a}}$ & $\mathrm{T}$ & $\mathrm{F}$ \\
\hline-2.5 & 48 & 270 & 79 & 293 & 81 & 266 & 96 & 310 & 85.3 & 284.8 \\
-5 & 48 & 292 & 57 & 294 & 80 & 269 & 94 & 309 & 77.0 & 291.0 \\
-10 & 52 & 283 & 98 & 259 & 81 & 267 & 99 & 304 & 92.7 & 278.3 \\
-20 & 51 & 296 & 51 & 296 & 80 & 266 & 99 & 304 & 76.7 & 290.5 \\
-40 & 51 & 276 & 78 & 299 & 77 & 273 & 85 & No data & 80.0 & 282.7 \\
-70 & 53 & 318 & 36 & 319 & 55 & 287 & 77 & 298 & 56.0 & 305.5 \\
-100 & 55 & 330 & 19 & 339 & 39 & 294 & 72 & 295 & 43.3 & 314.5 \\
-130 & 45 & 282 & 79 & 321 & 55 & 294 & 74 & 293 & 69.3 & 297.5 \\
\hline
\end{tabular}

${ }^{\text {a }}$ Season incomplete with the available data.

at shallow depths, decreasing quickly to reach an approximately constant value, which is different for each year. Those differences are evident in the daily cumulative plot (Fig. 8).

In detail, the FDD shows a common behavior along the study period, with a slight increase (in absolute values) from late February to late March. The FDD increases until October or November, but with evident flat periods along the freezing season, marking a non-constant evolution in those periods, until the end of the freezing season. This evolution patter is different for the TDD, with a more constant behavior along the thawing season, increasing from late February to late December, and finishing about late February or early March.

\section{$3.4 n$ factors}

We calculated freezing and thawing $n$ factors $\left(n_{\mathrm{f}}\right.$ and $n_{\mathrm{t}}$, respectively) by the use of Eqs. (5) and (6) using the previously described freezing and thawing indexes (Table 5). The resulting $\mathrm{n}_{f}$ are $0.54 \pm 0.30,0.40 \pm 0.25,0.57 \pm 0.30$ and $0.39 \pm 0.20$ for 2009 to 2012 , respectively. On the other hand, $n_{\mathrm{t}}$ values are $2.0 \pm 1.2,1.2 \pm 0.7,2.1 \pm 1.2$ and $2.1 \pm 1.2$, respectively, for the same years (Table 7).

Daily cumulative $n$ factors for each year (Fig. 9) change quickly at the beginning of the freezing or thawing seasons (they are low and therefore more sensitive to added values; Karunaratner and Burn, 2003, 2004).
Later in the season, they oscillate between more constricted values, trending to stabilize at the end of the season. The calculated $n_{\mathrm{f}}$ and $n_{\mathrm{t}}$ correspond to the value raised by them during the final stable period, while the mean $n_{\mathrm{f}}$ and $n_{\mathrm{t}}$ we also calculated provide higher values that depend on the amplitude of the oscillations shown along the respective season.

The evolution of $n_{\mathrm{f}}$ along the study period shows similar patterns. Except in 2010, where evolution is more gradual, the $n_{\mathrm{f}}$ increases quickly (in a few days) from late March to middle April. Two maximum values occur in April or May, and in July. From middle November to early December values are stable and similar to the calculated $n_{\mathrm{f}}$ (Table 7). This evolution is different for the $n_{\mathrm{t}}$ for which the values increase starting from early November to early December, reaching a maximum in January, decreasing until late March, and remaining completely stable for the entire freezing season, reaching a value similar to the calculated $n_{\mathrm{t}}$ (Table 7).

\subsection{Thermogram}

The thermograms provide a visual approach to the thermal evolution of the ground at different depths (Fig. 3). The thermograms of the study are for the 2009-2012 period, showing how the freezing $\left(0^{\circ} \mathrm{C}\right.$ isotherm) reaches the bottom of the borehole, and how the thawing effect also affects all the monitored depths. 
Table 4. Dates (day/month/year) of starting and finishing of the main zero curtain period during the early finish freezing thermal season, and their length in days ( ${ }^{\mathrm{a}}$ period still not finished at 22 January 2013).

\begin{tabular}{|c|c|c|c|c|c|c|}
\hline Depth & Start & Finish & Length & Start & Finish & Length \\
\hline & \multicolumn{6}{|c|}{2009} \\
\hline-2.5 & - & - & 0 & 19 Nov 2009 & 24 Dec 2009 & 35 \\
\hline-5 & - & - & 0 & 19 Nov 2009 & 15 Jan 2010 & 57 \\
\hline-10 & - & - & 0 & 19 Nov 2009 & 10 Jan 2010 & 52 \\
\hline-20 & 1 Apr 2009 & 26 Apr 2009 & 25 & 20 Nov 2009 & 22 Jan 2010 & 63 \\
\hline-40 & 1 Apr 2009 & 29 Apr 2009 & 28 & 20 Nov 2009 & 2 Jan 2010 & 43 \\
\hline-70 & 3 Apr 2009 & 13 May 2009 & 40 & 20 Nov 2009 & 15 Feb 2010 & 87 \\
\hline-100 & 5 Apr 2009 & 6 Jun 2009 & 62 & 25 Nov 2009 & 1 Mar 2010 & 96 \\
\hline \multirow[t]{2}{*}{-130} & 26 Mar 2009 & 15 Jun 2009 & 81 & 28 Nov 2009 & 2 Jan 2010 & 35 \\
\hline & \multicolumn{6}{|c|}{2010} \\
\hline-2.5 & - & - & 0 & 9 Oct 2010 & 31 Dec 2010 & 83 \\
\hline-5 & _- & _- & 0 & 9 Oct 2010 & 1 Jan 2011 & 84 \\
\hline-10 & _- & _- & 0 & 9 Oct 2010 & 2 Jan 2011 & 85 \\
\hline-20 & 14 Mar 2010 & $20 \mathrm{Apr} 2010$ & 37 & 9 Oct 2010 & 4 Jan 2011 & 87 \\
\hline-40 & 21 Mar 2010 & 2 May 2010 & 42 & 9 Oct 2010 & 14 Jan 2011 & 97 \\
\hline-70 & 23 Mar 2010 & 30 Jun 2010 & 99 & 9 Oct 2010 & 5 Feb 2011 & 119 \\
\hline-100 & 20 Mar 2010 & 9 Jul 2010 & 111 & 10 Oct 2010 & $22 \mathrm{Feb} 2011$ & 135 \\
\hline \multirow[t]{2}{*}{-130} & 22 Mar 2010 & $15 \mathrm{Jul} 2010$ & 115 & 3 Dec 2010 & 6 Feb 2011 & 65 \\
\hline & \multicolumn{6}{|c|}{2011} \\
\hline-2.5 & - & - & 0 & 7 Oct 2011 & 13 Dec 2011 & 67 \\
\hline-5 & - & - & 0 & 7 Oct 2011 & 16 Dec 2011 & 70 \\
\hline-10 & - & - & 0 & 7 Oct 2011 & 16 Dec 2011 & 70 \\
\hline-20 & 25 Mar 2011 & 4 Apr 2011 & 10 & 7 Oct 2011 & 16 Dec 2011 & 70 \\
\hline-40 & 1 Apr 2011 & 13 Apr 2011 & 12 & 8 Oct 2011 & $30 \operatorname{Dec} 2011$ & 83 \\
\hline-70 & 1 Apr 2011 & 11 May 2011 & 40 & 8 Oct 2011 & 13 Jan 2012 & 97 \\
\hline-100 & 2 Apr 2011 & 25 May 2011 & 53 & 9 Oct 2011 & 21 Jan 2012 & 104 \\
\hline \multirow[t]{2}{*}{-130} & 2 Apr 2011 & 10 Jun 2011 & 69 & 12 Dec 2011 & 21 Jan 2012 & 40 \\
\hline & \multicolumn{6}{|c|}{2012} \\
\hline-2.5 & - & - & 0 & 12 Nov 2012 & $-{ }^{a}$ & - \\
\hline-5 & 19 Mar 2012 & 23 Mar 2012 & 4 & 12 Nov 2012 & - & - \\
\hline-10 & 24 Mar 2012 & $1 \mathrm{Apr} 2012$ & 8 & 12 Nov 2012 & - & - \\
\hline-20 & 24 Mar 2012 & 4 Apr 2012 & 11 & 13 Nov 2012 & _- & _- \\
\hline-40 & 24 Mar 2012 & No data & - & No data & No data & - \\
\hline-70 & 30 Mar 2012 & 8 Jun 2012 & 70 & 14 Nov 2012 & - & - \\
\hline-100 & 2 Apr 2012 & 20 Jun 2012 & 79 & 15 Nov 2012 & - & - \\
\hline-130 & 4 Apr 2012 & 29 Jun 2012 & 86 & 12 Nov 2012 & - & - \\
\hline
\end{tabular}

In general, the freezing process starts from the surface and evolves gradually toward the depth, taking approximately 2 months to reach the maximum registered depth. However, the thawing process follows a different behavior because, although complete thawing of the ground occurs in approximately 1 month, it does not occur gradually, but in very quick events affecting only a range of depths. Thermograms show that the first few tens of centimeters (no more than $30 \mathrm{~cm}$ ) are the first to increase their temperature above $0^{\circ} \mathrm{C}$, while the rest of the ground remains frozen. This initial event occurs in 1-2 days. Only a few weeks later does another sector of the ground thaw. Although thermograms are affected by the lag of data between 70 and $100 \mathrm{~m}$ in depth, we could observe how this second thawing event affects the ground between 30 and $100 \mathrm{~cm}$. In a similar way to the shallower ground, this event occurs in 1-2 days, while the lower ground still remains frozen. Finally, a few weeks later, we have a complete thaw of the $130 \mathrm{~cm}$ of the monitored ground. This pattern in the thawing evolution is evident in 2010 and 2011. On the other hand, in 2009, we observe how the process is similar, except for the thawing of the bottom depths a few days earlier than the $30-70 \mathrm{~cm}$ sector.
Table 5. Thawing and freezing indexes $\left(0{ }^{\circ} \mathrm{C}\right.$ day $)$ of air and the ground at different depths (in $\mathrm{cm}$ ), and the resulting difference for each depth and year in the 2009-2012 period.

\begin{tabular}{|c|c|c|c|c|c|}
\hline Experiment & $\begin{array}{l}\text { Depth/ } \\
\text { height }\end{array}$ & 2009 & 2010 & 2011 & 2012 \\
\hline \multicolumn{6}{|c|}{ Thawing index (TDD) } \\
\hline Air & 160 & 72 & 91 & 142 & 126 \\
\hline \multirow[t]{8}{*}{ Ground } & -2.5 & 143 & 109 & 290 & 264 \\
\hline & -5 & 133 & 98 & 257 & 252 \\
\hline & -10 & 148 & 108 & 238 & 241 \\
\hline & -20 & 139 & 101 & 187 & 222 \\
\hline & -40 & 103 & 71 & 103 & No data \\
\hline & -70 & 73 & 47 & 53 & 90 \\
\hline & -100 & 63 & 16 & 17 & 52 \\
\hline & -130 & 30 & 23 & 21 & 31 \\
\hline \multicolumn{6}{|c|}{ Freezing index (FDD) } \\
\hline Air & 160 & -1107 & -725 & -1167 & -1012 \\
\hline \multirow[t]{8}{*}{ Ground } & -2.5 & -598 & -298 & -664 & -395 \\
\hline & -5 & -636 & -278 & -635 & -344 \\
\hline & -10 & -558 & -235 & -612 & -342 \\
\hline & -20 & -547 & -201 & -579 & -312 \\
\hline & -40 & -569 & -164 & -519 & No data \\
\hline & -70 & -503 & -128 & -442 & -223 \\
\hline & -100 & -378 & -121 & -403 & -174 \\
\hline & -130 & -347 & -105 & -333 & -152 \\
\hline \multicolumn{6}{|c|}{ Difference (FDD - TDD) } \\
\hline Air & 160 & -1035 & -634 & -1025 & -886 \\
\hline \multirow[t]{8}{*}{ Ground } & -2.5 & -455 & -189 & -374 & -131 \\
\hline & -5 & -503 & -180 & -378 & -92 \\
\hline & -10 & -410 & -127 & -374 & -101 \\
\hline & -20 & -408 & -100 & -392 & -90 \\
\hline & -40 & -466 & -93 & -416 & \\
\hline & -70 & -430 & -81 & -389 & -133 \\
\hline & -100 & -315 & -105 & -386 & -122 \\
\hline & -130 & -317 & -82 & -312 & -121 \\
\hline
\end{tabular}

In detail, the thawing of the shallowest ground does not start at the surface, but a few centimeters below it, such as occurs in early December 2009, middle November 2010, late November 2011, or middle December 2012. The thickness of these layers that thaw earlier than the surface, as well as their depth, is variable from one year to the other. This process also occurs during the thawing events during the early freezing season, such as in early April 2009, middle March 2010, or even in late April and middle March 2012. In these events, the ground initially frozen during the early freezing season is thawed immediately below the surface, while the surface and deeper ground still remain frozen. 
Table 6. Slope of TDD and FDD $\left({ }^{\circ} \mathrm{C}\right.$ day $\left.\mathrm{yr}^{-1}\right)$ for the air and ground at different depths in the 2009-2012 period.

\begin{tabular}{lccc}
\hline \multicolumn{3}{l}{ Slope $\left({ }^{\circ} \mathrm{C}\right.$ day $\left.\mathrm{yr}^{-1}\right)$} \\
Experiment & $\begin{array}{l}\text { Depth/ } \\
\text { height }\end{array}$ & TDD & FDD \\
\hline Air & 160 & 21.3 & 15.7 \\
Ground & -2.5 & 54.4 & 24.3 \\
& -5 & 51.6 & 27.1 \\
& -10 & 40.9 & 27.1 \\
& -20 & 33.5 & 32.7 \\
& -40 & 0.0 & 25.0 \\
& -70 & 5.7 & 52.6 \\
& -100 & -3.2 & 33.0 \\
& -130 & 0.1 & 35.7 \\
\hline & Mean & 23.7 & 35.7 \\
\hline
\end{tabular}

\subsection{Thermal profiles}

Thermal profiles show a v-shape design due to a decreasing temperature variability with the depth (Fig. 4). However, maximum and minimum temperature curves are asymmetrical with respect to the mean temperatures as well as with respect to the $0^{\circ} \mathrm{C}$ isotherm, which remains approximately constant along the depth of the borehole (Table 8). This mean temperature is lower than $0^{\circ} \mathrm{C}$ (approximately $-1^{\circ} \mathrm{C}$ ) in 2009 and 2011 , but slightly lower than $0^{\circ} \mathrm{C}$ in 2010 and 2012.

The thermal profile also shows how the thermal amplitude increases near the surface from $17^{\circ} \mathrm{C}$ to $26^{\circ} \mathrm{C}$ in the 2009-2012 period. In detail, the shape of the curves of the maximum and minimum daily temperatures along each year is also asymmetrical. On the one hand, both have different patterns for the first $40 \mathrm{~cm}$ with a non-linear curve, and for the $70-130 \mathrm{~cm}$ depths, with a linear curve. That asymmetry is recognizable in 2010 and 2011. In 2012, there are no data for the $40 \mathrm{~cm}$ depth sensor, which explains the gap in the curves at that depth. The slope (thermal gradient) of the deeper sectors $(70-130 \mathrm{~cm})$ of the curves is lower in 2010 and 2012 due to the approximately constant minimum temperature near the bottom of the borehole, especially in 2010 . On the other hand, the curves of maximum and minimum temperatures are also different, with a more pronounced curvature in the case of the positive temperatures, marking the higher thermal amplitude of positive temperatures.

In any case, the thermal profiles show that, for any year of the study period, the maximum temperature curves do not reach the $0{ }^{\circ} \mathrm{C}$ isotherm in the first $130 \mathrm{~cm}$ in depth. However, in 2010 and 2012, the maximum temperature is near that isotherm, especially considering the $\pm 0.5^{\circ} \mathrm{C}$ of the sensor accuracy.

Finally, neither maximum nor minimum temperatures converge, which means that the zero annual thermal amplitude

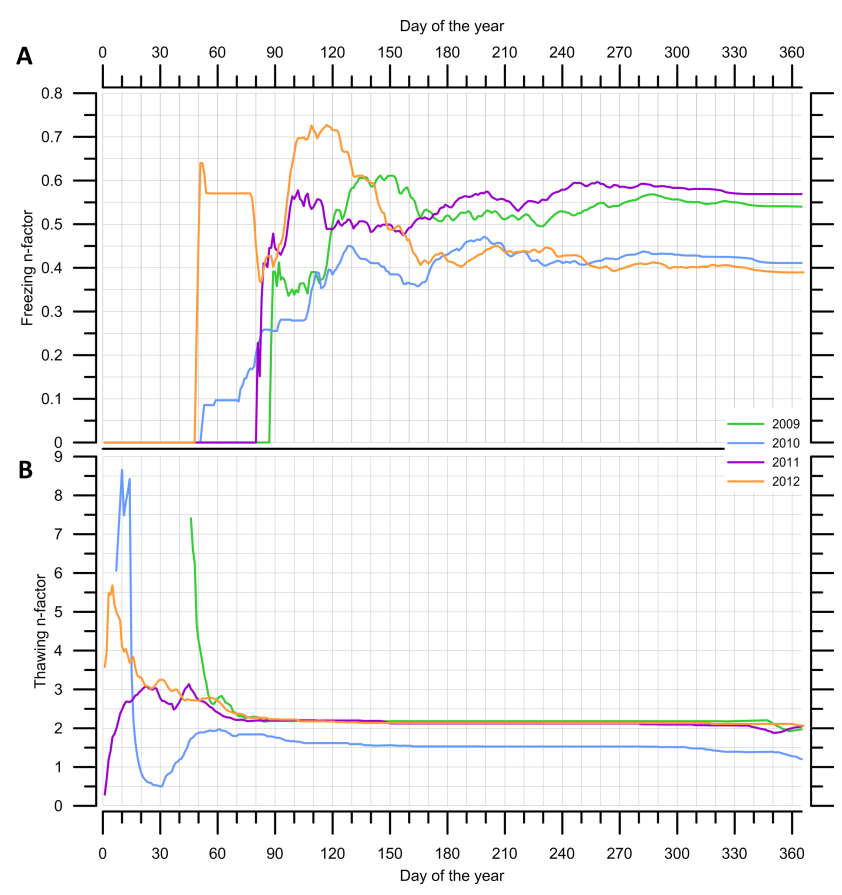

Figure 9. Freezing (top) and thawing (bottom) $n$ factors for the different years.

depth was not reached by the $130 \mathrm{~cm}$ deep borehole, and its calculation is required, such as we show below. In spite of that, this characteristic depth should be shallower in 2010 and 2012, when the thermal amplitude at $130 \mathrm{~cm}$ in depth is as small as $1{ }^{\circ} \mathrm{C}$.

\subsection{Top of permafrost depth}

The maximum of the mean daily temperatures registered by the deeper sensors installed in the borehole (i.e., 40, 70, 100 and $130 \mathrm{~cm}$ ) could be used to deduce by linear extrapolation the depth at which the permafrost, if it exists, should be located. We fit those values to a linear curve in a temperature versus depth plot, in order to calculate the intersection with the $0{ }^{\circ} \mathrm{C}$ isotherm (Fig. 4). The results are that the maximum temperatures should reach $0^{\circ} \mathrm{C}$, at $145,124,130$ and $135 \mathrm{~cm}$ in depth, from which we deduce that the depth of the top of the permafrost, if it exists, could be located at a mean depth of $134 \pm 22 \mathrm{~cm}$ at the study site during the 2009-2013 study periods.

\subsection{Zero annual thermal amplitude depth}

Based on the temperature amplitude at different depths for each year (Table 8), we fit an exponential curve following Eq. (1) (Fig. 4) in order to derive the depth of the zero annual thermal amplitude, i.e., the depth at which any climatic variation with periods smaller than one year is completely attenuated (at the range of the inverse of $e$ ). We obtained values of $d$ for the years 2009 to 2012, and assuming that the depth 
Table 7. Freezing and thawing indexes $\left(0{ }^{\circ} \mathrm{C}\right.$ day) of air and surface, and the resulting freezing and thawing $n$ factors (dimensionless) for the different years of the study period, based on calculated mean daily temperatures.

\begin{tabular}{llrrrr}
\hline & & 2009 & 2010 & 2011 & \multicolumn{1}{c}{2012} \\
\hline \multirow{2}{*}{ Air } & Thawing index & 72.29 & 90.86 & 141.74 & 126.20 \\
& Freezing index & -1106.69 & -725.35 & -1166.94 & -1012.44 \\
\multirow{3}{*}{ Surface $(2.5 \mathrm{~cm})$} & Thawing index & 142.67 & 109.43 & 290.11 & 260.27 \\
& Freezing index & -597.74 & -298.21 & -663.88 & -394.54 \\
\multirow{3}{*}{$n$ factor } & Freezing & 0.54 & 0.41 & 0.57 & 0.39 \\
& Thawing & 1.97 & 1.20 & 2.05 & 2.06 \\
\hline
\end{tabular}

of the zero annual thermal amplitude is approximately $3 d$, derived the zero annual thermal amplitude depth at approximately $2.2 \pm 0.2 \mathrm{~m}, 1.4 \pm 0.1 \mathrm{~m}, 2.0 \pm 0.2 \mathrm{~m}$ and $1.3 \pm 0.1$ $\mathrm{m}$, respectively, for the years 2009 to 2012 . Those results agree with what is shown in the thermal profiles, with higher thermal amplitudes at $130 \mathrm{~cm}$ in depth in 2009 and 2011 than in 2010 and 2012 (Fig. 4).

\subsection{Thermal and surface offsets}

The mean annual temperatures at different depths in the ground, as well as the mean annual temperature of the air at $1.6 \mathrm{~m}$ in height (Table 8), were used to derive both the thermal offset (surface-top of the permafrost) and surface offset (air-surface) (Table 9; Fig. 5). We obtained (in absolute values) $0.4{ }^{\circ} \mathrm{C}, 0.0{ }^{\circ} \mathrm{C}, 0.3{ }^{\circ} \mathrm{C}$ and $0.2{ }^{\circ} \mathrm{C}$ for the thermal offset in 2009 to 2012 , respectively, with a mean value of $0.2 \pm 1.0^{\circ} \mathrm{C}$. On the other hand, we also obtained (in absolute values) $1.8^{\circ} \mathrm{C}, 1.5^{\circ} \mathrm{C}, 1.7^{\circ} \mathrm{C}$, and $1.8^{\circ} \mathrm{C}$ for the surface offset in the same years, respectively (Fig. 5), with a mean value of $1.6^{\circ} \mathrm{C} \pm 1.0^{\circ} \mathrm{C}$. Both offsets show a similar pattern, with lower absolute values in 2010 , and a difference between them of approximately $1.7^{\circ} \mathrm{C}$. The mean (in absolute values) thermal offset is $0.2^{\circ} \mathrm{C}$, while the mean surface offset is $1.7^{\circ} \mathrm{C}$ (in absolute values).

\subsection{Apparent thermal diffusivity}

The main parameter describing the thermal properties of the materials of the ground is the thermal diffusivity. We calculated the apparent thermal diffusivity for the thawing season each year by the use of Eq. (7), and the resulting values (Table 10) range from $(3.3 \pm 0.2) 10^{-7} \mathrm{~m}^{2} \mathrm{~s}^{-1}$ in 2009 to $(5.6 \pm 0.1) 10^{-7} \mathrm{~m}^{2} \mathrm{~s}^{-1}$ in 2012. During the freezing season, due to the absence of well-defined sinusoidal temperature signals in the data series, it was only calculated in the 2010 freezing season, obtaining a lower value of $(1.86 \pm 0.7) 10^{-7} \mathrm{~m}^{2} \mathrm{~s}^{-1}$.
Table 8. Maximum, mean and minimum annual temperatures (in ${ }^{\circ} \mathrm{C}$ ) of the air and the ground at different depths (in $\mathrm{cm}$ ), and the calculated range and amplitude.

\begin{tabular}{|c|c|c|c|c|c|c|}
\hline \multirow[b]{2}{*}{ Measurement } & \multicolumn{6}{|c|}{2009} \\
\hline & Height/depth & $\operatorname{Max}$ & Mean & Min & Range & Amplitude \\
\hline Air & 160 & & -3.1 & & & \\
\hline \multirow[t]{9}{*}{ Ground } & -2.5 & 12.2 & -1.3 & -5.5 & 17.6 & 8.8 \\
\hline & -5 & 10.2 & -1.5 & -5.9 & 16.1 & 8.0 \\
\hline & -10 & 8.1 & -1.2 & -5.4 & 13.5 & 6.8 \\
\hline & -20 & 5.1 & -1.2 & -4.9 & 10.1 & 5.0 \\
\hline & -40 & 3.1 & -1.4 & -4.4 & 7.6 & 3.8 \\
\hline & -70 & 1.6 & -1.3 & -3.5 & 5.1 & 2.5 \\
\hline & -100 & 1.1 & -0.9 & -2.9 & 4.0 & 2.0 \\
\hline & -130 & 0.6 & -0.9 & -2.4 & 3.0 & 1.5 \\
\hline & \multicolumn{6}{|c|}{2010} \\
\hline Measurement & Height/depth & $\operatorname{Max}$ & Mean & Min & Range & Amplitude \\
\hline Air & 160 & & -1.7 & & & \\
\hline \multirow[t]{9}{*}{ Ground } & -2.5 & 14.1 & -0.2 & -5.4 & 19.4 & 9.7 \\
\hline & -5 & 11.4 & -0.2 & -5.0 & 16.4 & 8.2 \\
\hline & -10 & 8.3 & -0.1 & -4.0 & 12.4 & 6.2 \\
\hline & -20 & 6.4 & -0.1 & -3.1 & 9.5 & 4.8 \\
\hline & -40 & 2.3 & -0.2 & -1.9 & 4.2 & 2.1 \\
\hline & -70 & 0.9 & -0.2 & -1.4 & 2.3 & 1.1 \\
\hline & -100 & 0.2 & -0.3 & -1.3 & 1.5 & 0.8 \\
\hline & -130 & 0.2 & -0.2 & -1.1 & 1.3 & 0.7 \\
\hline & \multicolumn{6}{|c|}{2011} \\
\hline Measurement & Height/depth & $\operatorname{Max}$ & Mean & Min & Range & Amplitude \\
\hline Air & 160 & & -2.9 & & & \\
\hline \multirow[t]{9}{*}{ Ground } & -2.5 & 15.4 & -1.1 & -6.4 & 21.8 & 10.9 \\
\hline & -5 & 12.2 & -1.1 & -6.2 & 18.4 & 9.2 \\
\hline & -10 & 9.3 & -1.1 & -6.0 & 15.3 & 7.6 \\
\hline & -20 & 6.1 & -1.1 & -5.6 & 11.7 & 5.9 \\
\hline & -40 & 2.6 & -1.2 & -4.9 & 7.5 & 3.7 \\
\hline & -70 & 1.6 & -1.1 & -3.9 & 5.5 & 2.7 \\
\hline & -100 & 0.6 & -1.1 & -3.4 & 4.0 & 2.0 \\
\hline & -130 & 0.2 & -0.9 & -2.7 & 2.9 & 1.4 \\
\hline & \multicolumn{6}{|c|}{2012} \\
\hline Measurement & Height/depth & $\operatorname{Max}$ & Mean & Min & Range & Amplitude \\
\hline Air & 160 & & -2.4 & & & \\
\hline \multirow[t]{8}{*}{ Ground } & -2.5 & 18.4 & -0.6 & -8.6 & 27.0 & 13.5 \\
\hline & -5 & 14.5 & -0.4 & -7.3 & 21.8 & 10.9 \\
\hline & -10 & 12.0 & -0.5 & -5.7 & 17.7 & 8.9 \\
\hline & -20 & 10.8 & -0.4 & -3.6 & 14.5 & 7.2 \\
\hline & -40 & No data & No data & No data & - & - \\
\hline & -70 & 2.2 & -0.4 & -1.7 & 3.8 & 1.9 \\
\hline & -100 & 0.8 & -0.4 & -1.3 & 2.1 & 1.1 \\
\hline & -130 & 0.3 & -0.4 & -1.1 & 1.4 & 0.7 \\
\hline
\end{tabular}


Table 9. Surface and thermal offsets (in ${ }^{\circ} \mathrm{C}$ ) for each year of the study period.

\begin{tabular}{lllll}
\hline Measurement & 2009 & 2010 & 2011 & 2012 \\
\hline Thermal offset & -0.4 & 0.0 & -0.3 & -0.2 \\
Surface offset & -1.8 & -1.5 & -1.7 & -1.8 \\
\hline
\end{tabular}

\section{Discussion}

In this paragraph we present the detailed results of the ground thermal characterization of the active layer at the Limnopolar Lake CALM site, monitored between early 2009 and early 2013. The Limnopolar Lake CALM data could be used for comparisons with other CALM sites in the region, for example with the Crater Lake CALM site located on Deception Island, (e.g., Ramos et al., 2009a, 2009b, 2014; Ramos and Vieira, 2009; Vieira et al., 2010), to establish analogies and differences that could help to define the active layer characteristics (and permafrost depth) in this region. Also, we can compare the different CALM data with the regional weather and climate evolution in the South Shetland archipelago area. However, those results are also necessary to allow comparative analyses with other CALM sites all around the world with similar thermal properties and environmental conditions (climate, geology, topography, vegetation), as well as the basis for future frozen ground trend analyses taking into account the global warming scenarios.

Moreover, this characterization and the detailed analyses of some of those results could help us to understand the properties of the ground at this CALM site better, which is fundamental to the correct interpretation of the results from the past and future active layer thickness monitoring at this CALM site (e.g., de Pablo et al., 2013a). For that reason, here we study in depth some of the results shown above.

The values of the apparent thermal diffusivity that we have calculated for the thawing season, 3.3-5.6 $\times 10^{-7} \mathrm{~m}^{2} \mathrm{~s}^{-1}$ (Table 10), are similar to the values obtained in previous calculations by iterative methods (de Pablo et al., 2013a), and are consistent with sedimentary materials and soils with significant water content (e.g., Campbell and Norman, 2000). Those values point in the same direction as the thawing $n$ factor values we obtained close to 2 , which are usual values for sand and gravels (see Andersland and Ladanyi, 2003 and references therein). However, both apparent thermal diffusivity in freezing season and freezing $n$ factors are lower than expected for the same materials. This reduction in the values could be related to high water content (ice) during the freezing season, because the freezing $n$ factor for sand and gravel should be around 0.9 , but we obtained values of approximately 0.45 , which are approximately the values of sediments and soils under snow (see Andersland and Ladanyi, 2003 and references therein). The soils of the area in which the CALM site is located have been classified as sandy loam
Table 10. Thermal diffusivity calculated by exponential fitting of thermal amplitude in a selected period of time in which ground temperatures at 2.5, 5, 10 and $20 \mathrm{~cm}$ depth show a well-defined sinusoidal pattern.

\begin{tabular}{cccc}
\hline Thermal season & Dates & $\begin{array}{c}\text { Thermal diffusivity } \times 10^{-7} \\
\left(\mathrm{~m}^{2} \mathrm{~s}^{-1}\right)\end{array}$ & $R^{2}$ \\
\hline Thawing 2009 & 25-28 Feb 2009 & $4.51 \pm 0.2$ & 0.997 \\
Freezing 2009 & - & - & - \\
Thawing 2010 & 11-14 Feb 2010 & $3.69 \pm 0.2$ & 1.000 \\
Freezing 2010 & 19-22 Apr 2010 & $1.86 \pm 0.8$ & 0.995 \\
Thawing 2011 & 18-21 Jan 2011 & $3.30 \pm 0.7$ & 0.999 \\
Freezing 2011 & - & - & - \\
Thawing 2012 & 26-30 Dec 2011 & $5.56 \pm 0.1$ & 1.000 \\
Freezing 2012 & - & - & - \\
\hline
\end{tabular}

(Otero et al., 2013) with a sand content of approximately 46 to $80 \%$, and as coarse sands well selected - SW in the Unified Soils Classification System - (Molina et al., 2013), which agrees with our results and supports our interpretations of the nature of the materials and the description of the surface materials (de Pablo et al., 2013a; Otero et al., 2013).

The high water content of the soils was evident during the fieldwork since ponds were visible at located sites of the Limnopolar Lake CALM site (those located at lower elevations), and the water table level during the thawing season could be as high as a few centimeters (Fig. 3). Fieldwork at the end of the freezing season also revealed that the ground remained frozen and cemented by ice until the surface below the snow and ice layer covering the study area. Although we did not study here the snow thickness evolution, previous works on this area revealed that the snow cover thickness could reach more than $80 \mathrm{~cm}$ (de Pablo et al., 2013a), which provides, during the thawing season, a significant volume of water that could explain the enrichment in the water of the materials forming the ground.

The presence of water in the ground is also revealed by the long zero curtain periods we were able to define in the temperature data of the borehole (Fig. 7; Table 4). Zero curtain periods are usually related to ice melting because the received heat (from the Sun and the atmosphere) is consumed in the phase change process of the water better than by increasing the temperature of the ground materials (e.g., Andersland and Ladanyi, 2003). Therefore the long zero curtain periods that we observed at the end of the freezing season, as long as 90 days on the surface, imply high water content in the materials. Moreover, variable lengths of those zero curtain periods could be related to different heat exchange mechanisms, but also to different water content each year, probably due to differences in snow cover. However, zero curtain periods not only occur on the surface, but at all depths in the ground (for the $130 \mathrm{~cm}$ we are able to monitor), with slight increasing lengths with depth (Fig. 7), which could be related to the delay in the thermal wave penetration, but, in any case, due to water content in the ground. A singular behavior could be observed at $130 \mathrm{~cm}$ in depth, at which the length of the 
zero curtain periods at the end of the freezing period is approximately one third to half of the length of the same period at $100 \mathrm{~cm}$ in depth. This behavior does not occur during the zero curtain periods in the early freezing season, where the shallower ground does not show this thermal behavior (Table 4).

The absence of zero curtain periods in shallower ground during the early freezing period could be explained by the absence of water (at the borehole site). The complete melt of the snow cover in the early thawing season, the subsurface water flow and the evaporation could dry the upper $15 \mathrm{~cm}$ of the ground, while the rest of the terrain remains wet, which results in an increasing zero curtain period in the early freezing season (Table 4). This level is coincident with the level at which the $0{ }^{\circ} \mathrm{C}$ isotherm showed up on thermograms (Fig. 3). Firstly, freeze during the early freezing period, and the first in thaw during the late freezing season. In fact, this level could be related to subsurface water flow during the early snow cover melting at the borehole location, since the date of this shallow level thaw is coincident with the date of the snow cover melting (as seen in de Pablo et al., 2013a).

On the other hand, the lengths of zero curtain periods at the end of the freezing season are approximately similar for all depths (although slightly increasing with depth), except for the deeper ground $(130 \mathrm{~cm}$ in depth), where the length is clearly lower, as we described above. We propose here that the existence of liquid water at this level in the ground could explain this behavior. The water coming from snow cover melt could percolate in the ground until reaching this depth, melting the ice quickly before the thermal wave from the surface reaches that depth. Thermograms (Fig. 3) show that, in general, the ground thaws from the surface to the depth at the borehole location. The water could then not come from the surface directly on top of the borehole, but from the surrounding area.

Pictures of the basin show that the higher elevations of the ridge on which the CALM site is located are the first to lose the snow cover. The resulting melt water could percolate, producing a subsurface flow due to the $2 \%$ on the slope of the area. Moreover, taking into account that the Limnopolar Lake CALM site is located at the top and a flank of a low ridge in the middle of a basin (Otero et al., 2013; de Pablo et al., 2013a), we speculate that there is no regional subsurface source of the water, and all the water that could contain the materials in the ground should remain there from one year to the other, or infiltrate from the surface due to melting of the snow cover.

The reason this possible water flow occurs at that depth could be related, from our point of view, to the existence of permafrost (as an impermeable layer) below the active layer. We based this proposal on (1) the calculated depth of the top of the permafrost at approximately $134 \mathrm{~cm}$ in depth, which agrees with (2) the general reducing thawing period and indexes, and increasing freezing period and indexes with depth; (3) the ranges of depths at which the thawing season should be zero (if the ground remains constantly frozen), of approximately $180 \mathrm{~cm}$; (4) the range of depths at which the TDD should be zero, of approximately 105 to $168 \mathrm{~cm}$; (5) the null slope of the TDD along the studied period and the negative slope of FDD (increasing values trend); (6) the negative balance between TDD and FDD; (7) the stable negative mean temperature of the ground; and 8) the temperatures near $0{ }^{\circ} \mathrm{C}$ at $130 \mathrm{~cm}$ depth, as seen in the thermal profiles.

Although we could not confirm with our thermal data from the $130 \mathrm{~cm}$ deep borehole that there is a permafrost table below the active layer, we found its presence more reasonable than what we had expected (de Pablo et al., 2013a); a deeper borehole should be necessary to confirm and monitor it. However, other regional studies confirm the presence of permafrost on Byers Peninsula (e.g., López-Martínez et al., 1996; Serrano et al., 1996), and, for that reason, the permafrost existence proposed here agrees with the regional context. We also had direct evidence of a frozen table presence below the surface during the borehole drilling in February 2009. The drilling engine we used (STIHL BT 121) allows drilling of more than $2 \mathrm{~m}$ in sedimentary materials such as those forming the surface of both the Limnopolar Lake CALM sites.

The increasing drilling complexity from $110 \mathrm{~cm}$ in depth and the thermal behavior observed on the thermograms (Fig. 3) could point towards the presence of a former transition layer or a zone-like relict transition in the ground (e.g., Bockheim and Hinkel, 2005). Many other observations and calculations point in that direction. In fact, except near ponds on the CALM site, we never obtained deeper thawing depths of $100 \mathrm{~cm}$ when measuring the active layer thickness by mechanical probing (de Pablo et al., 2013a), and this agrees with the variable depths of the top of the permafrost we obtained of 124 to $145 \mathrm{~cm}$, and the variable depth of the zero annual thermal amplitude depth, between the 130 and $200 \mathrm{~cm}$ we calculated above. Thermographs also show how the ground below $100 \mathrm{~cm}$ in depth remained frozen for longer during the thawing season, although it finally melts in early February (except in 2013, when it still remained frozen at that date). In any case, this possible permafrost table should be considered unstable due to the mean temperatures of the ground: slightly lower than $0^{\circ} \mathrm{C}$ in the first $130 \mathrm{~cm}$ of the ground (Fig. 4). It is then sensitive to any change in the environmental conditions, especially air temperature and snow cover, which could produce a different thermal behavior in the ground, such as revealed by the thermograms (Fig. 3).

Finally, four years of data are not enough to analyze thermal trends of the ground, which, from different points of view, do not show a clear behavior in the study period. In fact, all the values and plots described and discussed here seem not to reflect a clear trend, but a peculiar behavior in which data from 2009 and 2011 show approximately similar values, but different than those obtained by data from 2010 and 2012, such as seen in thermal profiles (Fig. 4), thermal amplitude (Fig. 4), the zero annual thermal amplitude depth, surface and 
thermal offsets (Fig. 5), FDD and TDD indexes (Fig. 8), or thermogram (Fig. 3) plots. However, the mean air temperature has been slightly increasing in the study period, as well as the TDD indexes and the thawing $n$ factor. Although we could not conclude this from the available data, the ground seems to increase its temperature. To extend the time series data and to drill a deeper borehole in the area, it is fundamental to study the thermal trend and to monitor the active layer and the possible unstable permafrost layer and a possible former transitional layer we propose to exist below it.

In any case, the different behavior we observed in the data during the study period points toward the important role that water plays in the thermal evolution of the ground at this CALM site, probably due to the water infiltration from the surface due to snow cover melt. Analyzing this role in detail should be necessary to confirm the differences observed each year, and to allow an understanding of future behaviors, we could observe further data analysis in future years.

\section{Conclusions}

The analyses of thermal data from air and ground at different depths allowed us to reach the objective of the present research: to characterize the thermal behavior of the terrain at the Limnopolar Lake CALM site.

We characterized the ground of the CALM site for the study period with the following parameters:

- The mean ground temperature ranges from aprroximately $-1.2^{\circ} \mathrm{C}$ to $-0.2^{\circ} \mathrm{C}$, with thermal amplitudes of approximately $14^{\circ} \mathrm{C}$ at the surface and $0.7^{\circ} \mathrm{C}$ at $130 \mathrm{~cm}$ in depth.

- The freezing season starts between middle March and early April, and has a length of approximately 290 days, resulting in an FDD index that ranges from -105 to $-664{ }^{\circ} \mathrm{Cd}^{-1}$, gradually decreasing (in absolute value) with depth. The freezing $n$ factor ranges from 0.39 to 0.54 .

- The thawing season starts between late December and late February (depending on the depth), and has a length of 75 days, and its TDD index of the ground ranges from 16 to $290{ }^{\circ} \mathrm{C} \mathrm{d}^{-1}$. The thawing $n$ factor ranges from 1.02 to 2.06 .

- The mean thermal offset is $1.6{ }^{\circ} \mathrm{C}$, while the mean surface offset is $0.2^{\circ} \mathrm{C}$.

- The apparent thermal diffusivity during the thawing season ranged from $3.3 \times 10^{-7}$ to $5.56 \times 10^{-7} \mathrm{~m}^{2} \mathrm{~s}^{-1}$, values that agree with sedimentary materials with significant water content.

- Zero curtain periods exist during in both early and late freezing seasons, marking the presence of high water content in the ground, and their lengths increase with depth until 135 days, except at $130 \mathrm{~cm}$ in depth, showing similar values as in the surface during the late freezing season.

- The depth of the top of the permafrost should be approximately $135 \mathrm{~cm}$, and the zero annual thermal amplitude between 140 and $220 \mathrm{~cm}$ in depth.

- Thermograms show specific behaviors of the ground at different depths, especially the shallower $20 \mathrm{~cm}$ : the first of thawing at the end of the freezing season, and the ground below $100 \mathrm{~cm}$ in depth, which remains frozen for longer during the thawing season.

On the other hand, based on the data and their behavior, we propose the existence of a permafrost table below the active layer, whose top is located at a depth of approximately $120-140 \mathrm{~cm}$, which means that the temperature is near $0{ }^{\circ} \mathrm{C}$, and which therefore makes it sensitive to any environmental change, such as an increase in the air temperatures, snow cover changes, and the existence of groundwater. A possible former transitional layer from $100 \mathrm{~cm}$ in depth could exist, in agreement with the observations in the thermal data, during the borehole drilling and the mechanical probing, to measure the active layer thickness in each thawing season.

No trends could be derived from the available thermal data, although a slight warming of the air and ground appears on the data evolution fitting. Once the thermal characterization has been established by this work, to continue monitoring this the CALM site will contribute to the definition of the thermal trend and its evolution, and a deeper borehole will help to confirm the presence of permafrost and to characterize and monitor it. 


\section{Appendix A: Limnopolar Lake CALM site definition}

Table A1. Descriptive form of the Limnopolar Lake CALM-S site on Byers Peninsula (Livingston Island, Antarctica), and the monitoring instrumentation.

\begin{tabular}{l|l}
\hline CALM SITE & LIMNOPOLAR LAKE \\
\hline Site code & A25 \\
Site name & Limnopolar Lake \\
Responsible for data submission & M. A. de Pablo \\
Email address & miguelangel.depablo“-at-"uah.es \\
Institution/organization & Universidad de Alcalá (UAH) \\
Location description & Limnopolar Lake basin, Byers Peninsula, Livingston Island, Antarctica \\
Location lat. & $62^{\circ} 38^{\prime} 59.1^{\prime \prime} \mathrm{S}$ \\
Location lon. & $61^{\circ} 06^{\prime} 16.9^{\prime \prime} \mathrm{W}$ \\
Elevation avg. (m) & 80 \\
Methods grid & $100 \times 100 \mathrm{~m}$ \\
Methods: other &
\end{tabular}

- Air temperature (at $1.6 \mathrm{~m}$ height over the surface)

- Surface temperature

- Ground temperature (2 boreholes: 1.35 and $0.85 \mathrm{~cm}$ )

- Snow cover (1 mast with array an array of temperature sensors)

- Time-lapse camera (1 picture per day at noon)

- Distributed surface temperature (36 surface temperature sensors distributed in the CALM grid)

- Distributed snow cover ( 9 small masts distributed in the CALM grid with arrays of temperature sensors)

- Soils creeping (immediately outside the grid to ensure the non-disturbance of the surface during the ALT measurement)

\begin{tabular}{|c|c|}
\hline Outer coastal plain, dra & Outer coastal plain, drained lake basins \\
\hline Vegetation/classification & Mostly uncovered. Locally, small moss patches. \\
\hline Periglacial deposit. Tal & Periglacial deposit. Talus scree. Sand to gravel. \\
\hline Thaw depth measurements (year started) & 2009 \\
\hline Air temperature measurements (year started) & 2009 \\
\hline Snow cover measurements (year started) & 2009 \\
\hline Distributed snow cover measurements (year started) & 2013 \\
\hline Surface temperature measurements (year started) & 2009 \\
\hline Distributed surface temperature measurements (year started) & 2012 \\
\hline Ground temperature measurements (year started) & 2009 \\
\hline Time-lapse camera (year started) & 2009 \\
\hline Soil creeping (year started) & 2012 \\
\hline General description of soil moisture (dry, moist, wet, saturated) & $\begin{array}{l}\text { Dry to wet, depending of the sector of the CALM } \\
\text { site. Saturated at selected nodes. }\end{array}$ \\
\hline $\begin{array}{l}\text { Soil texture: if non-organic describes texture, if organic indicates thickness of the } \\
\text { organic layer }(\mathrm{cm}) \text {. }\end{array}$ & $\begin{array}{l}\text { Non-organic layer; mineral texture - variable from } \\
\text { sandy load to coarse gravel. Some nodes are silts }\end{array}$ \\
\hline \multicolumn{2}{|l|}{ Additional information } \\
\hline \multicolumn{2}{|c|}{$\begin{array}{l}\text { Additional thaw depth measurements are done at (A) } 3 \text { sites with } 1 \times 1 \mathrm{~m} \text { grids }(9 \text { nodes }) \text { at different locations inside the CALM site grid, } \\
\text { measured every } 2 \text { days to see the evolution of the soil thaw; (B) } 1 \text { detail site } 10 \times 10 \mathrm{~m} \text { ( } 36 \text { nodes) of a representative sector of the main } \\
\text { CALM site, to provide more detailed measurements of the active layer evolution. Those additional measurements are carried out when } \\
\text { there is enough available time during the Antarctic campaign in the protected region of Byers Peninsula. } \\
\text { During the ALT measurement by mechanical probing of the Limnopolar Lake CALM site, additional measurements of surface and soil } \\
\text { temperatures, and surface and subsurface }(5 \mathrm{~cm} \text { depth) unconfined, unconsolidated non-drained soil resistance, are also done in each } \\
\text { node, when time is available during the Antarctic campaign. }\end{array}$} \\
\hline
\end{tabular}


Table A1. Continued.

\section{SOIL DESCRIPTION:}

Sand to gravel

SAMPLING DESIGN AND METHOD:

$100 \times 100 \mathrm{~m}$ grid surveyed and permanently staked in the edge by stakes separated by $10 \mathrm{~m}$, yielding an $11 \times 11$ array of sampling nodes. Thaw depth sampling was conducted twice by manual probing at each node of the grid. The two values for each sampling point are averaged, yielding a maximum of 121 data points per grid per probing date during the thawing season (normally the last days of January or early February, due to logistical requirements during Antarctic campaigns). The active layer was not measured at locations where grid points are covered by a thick layer of ice and snow, since the ground remains frozen.

Other information

We have instruments measuring different parameters: air temperature (hourly measurements by the Tinytag device by Gemini), surface temperature ( $3 \mathrm{~h}$ measurements by iButton devices from Maxim), snow thickness (based on the use of an array of temperature sensors mounted on a wooden mast at 2.5, 5, 10,20,40,80, and $160 \mathrm{~cm}$ height by iButton devices), and ground temperature, at 2 boreholes of $135 \mathrm{~cm}$ and $85 \mathrm{~cm}$ depth. Measurements are done at 2.5, 5, 10, 20,40,70,100, and $130 \mathrm{~cm}$, and 2.5, 5, 10, 20, 40, 70, and 80 cm, respectively, by iButton devices. Moreover, we installed 9 small masts regularly distributed at the CALM site to derive snow thickness. 36 temperature sensors, regularly distributed at the CALM site, also measure surface temperature along the grid. A meteorological station was installed in 2006 by another research team, who search their data with us to complete our data. A time-lapse camera acquires 1 image per day of the CALM site and the surrounding area in order to observe the evolution of the weather, snow coverage and watersheet of the nearby Limnopolar Lake.

References

- de Pablo, M. A., Blanco, J. J., Molina, A., Ramos, M., Quesada, A., and Vieira, G.: Interannual active layer variability at the Limnopolar Lake CALM site on Byers Peninsula, Livingston Island, Antarctica, Antarct. Sci., 25, doi:10.1017/S0954102012000818, 167-180, 2013a.

- Otero, X. L., Fernández, S., de Pablo, M. A., Nizoli, E. C., and Quesada, A.: Plant communities as a key factor in biogeochemical processes involving micronutrients ( $\mathrm{Fe}, \mathrm{Mn}, \mathrm{Co}$, and $\mathrm{Cu}$ ) in Antarctic soils (Byers Peninsula, maritime Antarctica), Geoderma, 195-196, 145-154, 2013.

- de Pablo, M. A., Ramos, M., and Molina, A.: Active Layer evolution (2009-2011) at "Limnopolar Lake" CALM-S site on Byers Peninsula, Livingston Island (Antarctica), IN III-Congreso Ibérico de la IPA, Piornedo, Spain, Abstracts, 2011.

- de Pablo, M. A., Ramos, M., Vieira, G., and Quesada, A.: A new CALM-S site on Byers Peninsula, Livingston Island, Antarctica, in: Ambientes Periglaciares, Permafrost y Variabilidad Climática: II Congreso Ibérico de la International Permafrost Association, edited by: Blanco, J. J., de Pablo, M. A., and Ramos, M., Servicio de Publicaciones de la Universidad de Alcalá, Alcalá de Henares, 153-159, 2010.

\begin{tabular}{lrlrlll}
\hline Data & & & & & & \\
\hline Year & 2009 & 2010 & 2011 & 2012 & 2013 & 2014 \\
\hline Mean active layer thickness $(\mathrm{cm}):$ & 46.8 & 43.4 & 40.5 & 39.1 & 11.7 & \\
Mean air temperature $\left({ }^{\circ} \mathrm{C}\right):$ & -2.91 & -1.61 & -3.07 & -2.46 & - & \\
Mean surface temperature $\left({ }^{\circ} \mathrm{C}\right):$ & -1.40 & -0.62 & -1.08 & -0.11 & - & \\
Maximum snow cover $\left({ }^{\circ} \mathrm{C}\right):$ & 80 & 80 & 40 & 80 & - & \\
\hline
\end{tabular}


Acknowledgements. This research was funded by the CTM201115565-E, CTM2009-10165 and CTM2008-02042-E/ANT projects. The authors thank the Spanish Polar Program, the Spanish Polar Committee, the Unit of Marine Technology and the Spanish Army for their contributions that made possible the development of the fieldwork campaigns on Byers Peninsula, Antarctica. Our special thanks to mountain guides Hilo and Arkaitz for their support during the fieldwork campaigns. The authors thank the anonymous referees for their comments that improved the original manuscript.

Edited by: M. Oliva

\section{References}

Andersland, O. B. and Ladanyi, B.: Frozen Ground Engineering, 2nd edn., John Wiley \& Sons Inc, UK, 2003.

Bañón, M.: Meteorological observationsat the Spanish Antarctic Base Juan Carlos I., Spanish Ministry of Environment, National Institute of Meteorology, Madrid, 2001 (in Spanish).

Bañón, M., Justel, A., Velázquez, D., and Quesada, A.: Regional weather survey in Byers Peninsula, Livingston Island, South Shetland islands, Antarctica, Antarct. Sci., 25, 146-156, doi:10.1017/S0954102012001046, 2013.

Bjork, S., Hiort, C., Ingolfsson, O., Zale, R., and Ising, J.: Holocene deglaciation chronology from lake sediments, in: Geomorphological Map of Byers Peninsula, Livingston Island, edited by: López-Martínez, J., Thompson, M. R. A., and Thomson, J. W., BAS Geomap Series, Sheet 5-A, Scale $1: 25000$, British Antarctic Survey, Cambridge, 49-51, 1996.

Bockheim, J. G. and Hinkel, K. M.: Characteristics and significance of the transition zone in drained thaw-lake basins of the Arctic Coastal Plain, Alaska, Arctic, 58, 406-417, 2005.

Brown, J., Nelson, F. E., and Hinkel, K. M.: The circumpolar active layer monitoring (CALM) program research designs and initial results, Polar Geography, 3, 165-258, 2000.

Campbell, G. S. and Norman, J. M.: An Introduction to Environmental Biophysics, 2nd edn., Springer, New York, 286 pp., 2000.

de Pablo, M. A., Ramos, M., Vieira, G., and Quesada, A.: A new CALM-S site on Byers Peninsula, Livingston Island, Antarctica, in: Ambientes Periglaciares, Permafrost y Variabilidad Climática: II Congreso Ibérico de la International Permafrost Association, edited by: Blanco, J. J., de Pablo, M. A., and Ramos, M., Servicio de Publicaciones de la Universidad de Alcalá, Alcalá de Henares, 153-159, 2010.

de Pablo, M.; Ramos, M. and Molina, A. Active Layer evolution (2009-2011) at "Limnopolar Lake" CALM-S site on Byers Peninsula, Livingston Island (Antarctica), in: Criosferas, Suelos Congelados y Cambio Climático, edited by: Valcarcel, M. and Carrera, P., III-Congreso Ibérico de la IPA, Universidad de Santiago de Compostela, 75-78, 2011.

de Pablo, M. A., Blanco, J. J., Molina, A., Ramos, M., Quesada, A., and Vieira, G.: Interannual active layer variability at the Limnopolar Lake CALM site on Byers Peninsula, Livingston Island, Antarctica, Antarct. Sci., 25, doi:10.1017/S0954102012000818, 167-180, 2013a.

de Pablo, M. A., Pamler, W., and Ramos, M.: CALM-DAT: software for the analysis of active layer and permafrost thickness, evolution and thermal behavior, First approach, Extended abtracts of the IV Congreso Ibérico de la International Permafrost Association, Vall de Nuria, Spain, in press, 2013b.

Karunaratne, K. C. and Burn, C. R.: Freezing $n$-factors in discontinuous permafrost terrain, Takhini River, Yukon Territory, Canada, in: Proceedings of the 8th International Conference on Permafrost, University of Zurich-Irchel, Zurich, 519-524, 2003.

Karunaratne, K. C. and Burn, C. R.: Relations between air and surface temperature in discontinuous permafrost terrain near Mayo, Yukon Territory, Can. J. Earth Sci., 41, 1437-1451, 2004.

Lewkowicz, A. G.: Evaluation of miniature temperature-loggers to monitor snowpack evolution at mountain permafrost sites, northwestern Canada, Permafr. Periglac. Proc., 19, 323-331, 2008.

López-Martinez, J., Thomson, M. R. A., and Thomson, S. N. (Eds.): Geomorphological map of Byers Peninsula, Livingston Island, BASGEOMAP Series, Sheet 5-A, Scale 1:25000, British Antarctic Survey, Cambridge, 1996.

Lopez-Martínez, J., Serrano, E., Schmid, T., Mink, S., and Lines, C.: Periglacial processes and landforms in the South Shetland Islands (northern Antarctic Peninsula region), Geomorphology, 155, 62-79, 2012.

Lunardini, V. J.: Theory of $n$ factors and correlation of data. In Proceedings, 3rd International Conference on Permafrost, Edmonton, Alberta, July 10-13, 1978, National Research Council of Canada, Ottawa, ON, 1, 40-46, 1978.

Matsuoka, N.: Monitoring periglacial processes: towards construction of a global network, Geomorphology, 80, 20-31, 2006.

Matsuoka, N. and Humlum, O.: Monitoring periglacial processes: new methodology and technology, Permafrost Periglac., 14, 299303, 2003.

Molina, A., de Pablo, M. A., Bardají, T., and Ramos, M.: Caracterización granulométrica y mineralógica de los diferentes tipos de suelos presentes en las islas Livingston y Decepción (Shetland del Sur, Antártida), Extended abtracts of the IV Congreso Ibérico de la International Permafrost Association, Vall de Nuria, Spain, in press, 2013.

Nelson, F. E., Shiklomanov, N. I., Hinkel, K., and Christiansen, H.: Introduction: the Circumpolar Active Layer Monitoring Network (CALM) workshop and CALM II program, Polar Geography, 28, 253-266, 2004.

Otero, X. L., Fernández, S., de Pablo, M. A., Nizoli, E. C., and Quesada, A.: Plant communities as a key factor in biogeochemical processes involving micronutrients $(\mathrm{Fe}, \mathrm{Mn}, \mathrm{Co}$, and $\mathrm{Cu}$ ) in Antarctic soils (Byers Peninsula, maritime Antarctica), Geoderma, 195-196, 145-154, 2013.

Ramos, M. and Vieira, G.: Evaluation of the ground surface Enthalpy balance from bedrock temperatures (Livingston Island, Maritime Antarctic), The Cryosphere, 3, 133-145, doi:10.5194/tc-3-133-2009, 2009.

Ramos, M., Vieira, G., Gilichinsky, D., and de Pablo, M. A.: Establecimiento de estaciones de medida del régimen térmico del permafrost en el área de "Crater Lake", Isla Decepción (Antártida), in: Ambientes Periglaciares, Permafrost y Variabilidad Climática: II Congreso Ibérico de la International Permafrost Association, edited by: Blanco, J. J., de Pablo, M. A., and Ramos, M., Servicio de Publicaciones de la Universidad de Alcalá, Alcalá de Henares, 93-108, 2009a.

Ramos, M., Hasler, A., Vieira, G., Gruber, S., and Hauck, C.: Setting up boreholes for permafrost thermal monitoring on Liv- 
ingston Island in the Maritime Antarctic, Permafrost Periglac., 20, 57-64, 2009b.

Ramos, M., de Pablo, M. A., Sebastian, E., Armiens, C., and Gómez-Elvira, J.: Temperature gradient distribution in permafrost active layer, using a prototype of the Ground Temperature Sensor (REMS-MSL) on Deception Island (Antarctica), Cold Reg. Sci. Technol., 72 23-32, 2012.

Ramos, M., de Pablo, M. A., Vieira, G., Molina, A., and Abramov, A.: Interannual active layer thermal and dynamics evolution at the Crater Laker CALM site, Deception Island, Antarctica (2006-2012), Solid Earth, submitted, 2014.

Serrano, E., Martínez de Pisón, N. E., and López-Martínez, J.: Periglacial and nival landforms and deposits, edited by: LópezMartínez, J., Thompson, M. R. A., and Thomson, J. W., eds. Geomorphological map of Byers Peninsula, Livingston Island, BAS Geomap Series, Sheet 5-A, Scale 1:25 000, Cambridge, British Antarctic Survey, 28-34, 2010.
Toro, M., Camacho, A., Rochera, C., Rico, E., Bañón, M., Fernández-Valiente, E., Marco, E., Justel, A., Vincent, W. F., Avendaño, M. C., Ariosa, Y., and Quesada, A.: Limnological characteristics of the freshwater ecosystes of Byers Peninsula, Livingston Island, Antarctica, Polar Biol., 30, 635-649, 2007.

Toro, M., Granados, I., Pla, S., Giralt, S., Antonioades, D., Galán, L., Martínez-Cortizas, A., Lim, H. S., and Appleby, P. G.: Chronostratigraphy of the sedimentary record of Limnopolar Lake, Byers Peninsula, Livingston Island, Antarctica, Antarct. Sci., 26, 198-212, doi:10.1017/S0954102012000788, 2013.

Vieira, G., Bcokheim, J., Gugliemin, M., Balk, M., Abramov, A., Boelhouwers, J., Cannone, N., Ganzert, L., Gilichinsky, D. A., Gotyachkin, S., López-Martínez, J., Meiklejhon, I., Raffi, R., Ramos, M., Schaefer, C., Serrano, E., Simas, F., Sletten, R., and Wagner, D.: Thermal state of permafrost and active-layer monitoring in the Antarctic: advances during the International Polar Year 2007-2009, Permafrost Periglac., 21, 182-197, 2010. 